\title{
Incredible Utility: The Lost Causes and Causal Debris of Psychological Science
}

\author{
John E. Richters (D) \\ Rockville, MD, USA

\begin{abstract}
Variable-oriented, sample-based individual differences research strategies and statistical modeling approaches to causal-theoretical inference depend on their logic, coherence, justification, and presumed heuristic value on the tacit assumption that individuals are qualitatively the same, homogeneous with respect to the psychological structures and processes underlying their overt functioning, and that quantitative differences between them are produced by exactly the same psychological structures functioning in exactly the same way within each individual. This psychological homogeneity assumption, however, is demonstrably false and invalidated by a substantial body of uncontested scientific evidence documenting psychological heterogeneity as a ubiquitous, defining characteristic of human functioning. This irreconcilable mismatch between the psychological homogeneity assumption of the paradigm and the psychologically heterogeneous realities of its phenomena renders the individual differences methodology intrinsically incapable of advancing theoretical knowledge about the causes of psychological and behavioral phenomena. A detailed look at this mismatch reveals also that it holds considerable explanatory power as the root cause of the slow theoretical progress and replication failures of psychological research, as well as the driving force behind psychology's inability to relinquish its controversial reliance on null hypothesis significance testing as a justification standard for evaluating theoretical claims.
\end{abstract}

\section{The incredible utility of perpetual motion}

Mouvement perpetua, perpetua mobilia, perpetual motion. The holy grail of inventors dating back to the $13^{\text {th }}$ century; the zenith of technological achievement. An intricately designed, elegantly complex, finely tuned device for generating free energy. Something for nothing; the ultimate free lunch. A near-perfect invention with but a single flaw: perpetual motion devices don't work, cannot work because the first and second laws of thermodynamics preclude the possibility of the machine that can produce more energy than it consumes anywhere in the known universe. Which is why perpetual motion inventions are also unpatentable.

For almost any other invention, the United States Patent and Trademark Office (USPTO) will accept an applicant's utility claims at face value with the openeyed credulity of a trusting child. For almost any other invention, in fact, an inventor's utility assertions will be considered presumptively valid under U.S. Patent law and sufficient to satisfy the de minimis credible utility requirement for patent protection as a useful invention. But perpetual motion is not any other invention. It is the most notorious and derided device in the history of inventions. So completely and unambiguously devoid of credible utility that it is explicitly designated in U.S. patent law as an incredible utility (United States Patent and Trademark Office, 2019, pp. 2100-110) and serves as the de facto prototype of wholly inoperable, useless and therefore unpatentable inventions.

Although the patent law forbids the patenting of useless inventions, it also forbids the USPTO from rejecting an invention on incredible utility grounds unless it can prove that the invention is incapable of functioning as claimed. That is, the patent examiner must shoulder the burden of challenging the presumptive validity of an inventor's utility claims by establishing prima facie that they would not be considered credible by "person having ordinary skill in the art" (PHOSITA) - a hypothetical person presumed to be familiar with the invention-relevant scientific and engineering literature (United States Patent and Trademark Office, 2019, pp. 2100-110). In the specific case of alleged perpetual motion devices, the incredible utility rejection will be grounded in the 
established scientific consensus (for which the PHOSITA serves as a stand-in) that perpetual motion is epistemically impossible-cannot be achieved in a world governed by the laws of thermodynamics, which have been shown mathematically, theoretically, and empirically to be universally valid and invariant over time. As summarized more succinctly by Sir George Anthony Mann in a recent perpetual motion decision handed down by the British Patent Court: "Mr. Crowley may be correct [about] ... the operation of [his] machine [in] an ideal world ... However, Mr. Crowley and the rest of us do not live in such a world" (Peter Crowley v. Comptroller General of Patents, 2014).

\section{Incredible utility thesis}

Individuelle Unterschiede, différences individuelles, individual differences: the eponymous object of American psychology's observational research paradigm for more than 100 years. Inspired by Darwin, inaugurated by Galton, invigorated by Pearson, incubated in positivism, and imprinted on the epistemological foundations of logical positivism, the individual differences paradigm has defined the language, concepts, research practices and scientific standards of psychological science since the early decades of the 20th century (Borsboom et al., 2009; Cronbach, 1957). Embraced as a methodological solution to what John Stuart Mill had called the "backward state of the (19th century) moral sciences" (Mill, 1843, p. x), the paradigm promises a statistical end-run around the intensive study of individuals by privileging the study of populations over persons, patterns over particulars, and quantitative over qualitative methods in the search for causes of psychological and behavioral phenomena. Substituting aggregates for individuals, the paradigm offers a direct quantitative wormhole to causal knowledge by relying on the brute force computational power of matrix algebra to examine variable-based patterns of quantitative differences between them.

Like all research paradigms, the individual differences methodology necessarily relies on idealized assumptions and models as a quid pro quo precondition for the scientific activities necessary to realize its potential. Few paradigms, however, offer so much for so little. In exchange for the simplifying assumption that individual differences in overt functioning are caused by exactly the same psychological structures and processes in exactly the same way in all individuals the paradigm promises a finely tuned statistical methodology capable of deciphering the algorithms of the human brain and unraveling the causes of psychological and behavioral phenomena. As Sir George Mann observed about the fatal design flaw in Mr. Crowley's free energy device, however, we do not live in such a world. The idealized world presumed by the individual differences methodology is rendered impossible by the human brain's extraordinary adaptive capacities for progressive experience-based modifications and elaborations of psychological structures and processes across each individual's lifespan. And in a world populated with psychologically heterogeneous individuals-the world we live in - the putative causal utility of the individual differences methodology is, like Mr. Crowley's free energy claims, an epistemic impossibility. Like Mr. Crowley's device, it is a nearperfect methodology with but a single flaw: It doesn't work, it cannot work, because it is predicated on a psychological homogeneity assumption that cannot be true. The individual differences paradigm, in short, is the methodological equivalent of an incredible utility.

My central objective for the remainder of this paper is to establish a PHOSITA case for the merits and implications of the incredible utility thesis by examining evidence and arguments in support of five interrelated conclusions:

First, variable-oriented, sample-based individual differences research strategies and statistical modeling approaches to causal-theoretical inference depend for their logic, coherence and justification on the tacit assumption that individual sample members are psychologically homogeneous-isomorphic, qualitatively the same-with respect to the theory-relevant psychological structures and processes underlying their overt functioning in a particular study. Restated, the objects of empirical inquiry in individual differences research are not the concrete, living individuals of ultimate theoretical interest. Rather, they are statistical aggregates reflecting quantitate differences between individuals whose psychological structures and processes are presumed a priori to have produced those data points in exactly the same way.

Second, the psychological homogeneity assumption is a logically necessary precondition for the paradigm's corollary assumptions that: (1) individual differences in any particular pattern of overt functioning (e.g., shyness, sociability, depression, aggression, selfesteem, etc.) are reflections of unknown, complex, but nonetheless unitary causal structures that are invariant across individuals, (2) each theory-relevant variable under consideration in a particular study either does or does not exert a causal influence on the overt 
functioning of every sample member and, if so, the path of causal transmission (e.g., direct, mediated, bidirectional) is exactly the same; (3) correlations between and among variables are necessary (but insufficient) for establishing causal relations, and (4) the unwanted influences of theory-irrelevant nuisance variables can be removed using statistical adjustmentso-called control-procedures.

Third, the psychological homogeneity (i.e., isomorphism) assumption is undermined by a substantial body of research and theory documenting the unique design plasticity of the human brain and its extraordinary capacities for progressive use-dependent and experience-based structural modifications and elaborations across individual lifespans. Psychological heterogeneity is a sufficiently ubiquitous characteristic of human functioning that a PHOSITA would consider the psychological homogeneity assumption and its corollaries-and, by extension, the presumed utility of the individual differences methodology for identifying causes-to be incredible under most circumstances in light of contemporary knowledge.

Fourth, as a consequence of this unrecognized heterogeneity, inter-individual correlations that are routinely interpreted as indicators of a presumed unitary causal structure are instead far more likely to reflect the uninterpretable causal debris of heterogeneous psychological and causal structures, the number and nature of which lie beyond the reach of homogeneitybased research methods and data-analytic strategies.

Fifth, the psychological homogeneity assumption and corollaries underlying the individual differences methodology render it intrinsically incapable of shouldering the complex methodological challenges of studying structurally and causally heterogeneous psychological phenomena.

The core of my thesis, in a nutshell, is that the individual differences paradigm is inherently incapable of identifying the causes of psychological and behavioral phenomena because it is predicated on the tacit assumption that they don't exist-that individuals are instead structurally and functionally equivalent to the passive, structurally homogeneous objects of classical physics. The empirical literature reveals no evidence that the vast majority of researchers are aware of their methodological reliance on the homogeneity premise and its corollaries. Moreover, given that psychological homogeneity is invalidated by the evidence of our own senses, virtually all psychological theories, and a substantial body of uncontested empirical and theoretical literature, it is difficult to imagine on what grounds any contemporary psychologist would feel comfortable defending it. Nonetheless, a straightforward reverse engineering analysis reveals that every stage of the prototypical individual differences research process-from initial study design through data analysis and interpretation-is intelligible and justified only if the psychological homogeneity assumption and its corollaries are valid.

My discussion below is organized into six sections, corresponding to the central claims and methodological implications of the incredible utility thesis. In the first section, I descend into the methodological plumbing and wiring of 39 recently published longitudinal studies that are prototypical of the individual differences paradigm. Drawing on a detailed methodological assay of their major design characteristics, I illustrate how the psychological homogeneity assumption serves as a load-bearing support beam for the scaffolding of corollaries on which investigators tacitly rely to negotiate the inferential passage from aggregate-level data patterns to individual-level causal conclusions about intraindividual psychological processes and behaviors. In the second section, I examine the historical origins of the individual differences paradigm to show that the psychological homogeneity assumption was embraced initially by the fledgling science of psychology for reasons of expediency, not scientific merit. It was a pragmatically necessary choice in a deeply positivist climate that permitted no alternatives, and has never been-and cannot beexplained, defended, or justified on the merits of its fidelity to the known characteristics of psychological and behavioral phenomena. In the third section, I synthesize evidence from evolutionary biology, the neurosciences, and related fields to establish a scientific case for something everyone recognizes and understands intuitively: the psychological homogeneity assumption and its corollaries are manifestly false and irretrievably wrong-cannot be true. In the fourth section I draw on thought experiments, hypothetical scenarios, and data-analytic exercises to illustrate at a granular level precisely why the data analytic, statistical control and causal modeling strategies predicated on the psychological homogeneity assumption and its corollaries are inherently incapable of shouldering the methodological and statistical burdens imposed by psychological and causal heterogeneity. In the fifth section, I explain how the individual differences methodology weaponizes psychological homogeneity and its corollaries into a self-cloaking, self-perpetuating paradigm flaw by relying on them as the de facto reference standard for evaluating their own merits. Finally, in the sixth section, I turn to the obvious 
question lurking behind the evidence and arguments of preceding sections by considering the implications of the incredible utility thesis for methodological reforms in psychological research.

\section{The plumbing and wiring of individual differences methodology}

My purpose in what follows is to illustrate how the psychological homogeneity assumption functions as the hidden load-bearing support beam for a scaffolding of interdependent corollary assumptions underlying the logic and rationale of individual differences research. As an aid to this illustration, I draw on an assay of the key design characteristics of all 39 longitudinal research studies published in the first 2019 issue of 11 leading psychology journals that were designed to advance causal/theoretical knowledge about psychological processes underling the overt functioning of individuals using the individual differences methodology (see Table 1). At first glance, these studies appear to share little in common. They are animated by a wide variety of different substantive and theoretical issues, focus on different subject populations over widely varying longitudinal time spans, and employ a broad range of different sampling approaches, assessment instruments, data reduction strategies, and statistical modeling techniques.

If we focus instead on the methodological plumbing and wiring of tacit assumptions beneath the surface of these design particulars, however, the Table 1 studies are indistinguishable from one another. Prototypical of research formulated within the individual differences framework, the major design characteristics of all 39 studies stem from and are wedded to the foundational psychological homogeneity assumption and its scaffolding of interdependent corollaries (see Incredible utility thesis). As implicit background assumptions baked into the tacit logic of the individual differences methodology, they remain hidden from view in the everyday discourse and activities of psychological research and are difficult to recognize without deliberate effort (see How the individual differences paradigm perpetuates itself). As I illustrate in the analysis that follows, however, psychological homogeneity and its corollaries are indispensable to bridging an otherwise-unbridgeable gap between the animating individual-level theoretical models of individual differences research and the aggregate-level empirical models on which researchers rely to interpret the theoretical relevance of study findings.

\section{Individual-level theoretical models}

Consider for a moment the theoretical language commonly used in the Introduction and Discussion sections of individual differences empirical journal articles, including those listed* in Table 1:

acts, activates*, aggravates, agitates, aids, alleviates, allows, ameliorates, amplifies, arouses, attracts, bestows, biases, blunts*, bolsters, boosts, breaks, buffers*, builds, buttresses, comforts, compounds, compromises*, conditions, confers*, contributes*, conveys, counteracts, creates*, cultivates, curbs, damages, dampens, decreases, defuses, determines, detracts, develops*, diminishes, discourages, displaces, disposes, disrupts*, distorts, distracts, drives, eases, effects*, elicits, empowers, enables, encodes*, encourages, energizes, enforces, engenders, enhances*, enriches, entices, erodes*, establishes, evokes, evolves*, exacerbates*, excites, exhausts, expresses, extinguishes, facilitates, fades, forges, fortifies, fosters*, functions*, furnishes, galvanizes, generates*, governs, guides*, hampers, handicaps, harms*, heightens*, hinders, impacts*, impairs, impedes, improves, increases*, induces, influences*, informs*, inhibits*, injures, initiates, inspires, intensifies*, interacts, interferes*, interrupts, invigorates, invokes, irritates, kindles, lays, leads*, lessens* ${ }^{*}$ limits, lowers*, magnifies, makes*, maintains, marshals, mediates*, minimizes*, mitigates, modifies, motivates, obscures, obstructs, operates, permits, places*, plays*, potentiates, predisposes, prepares, pressures, prevents, produces, promotes*, prompts, propels, protects*, provokes*, raises, reduces, regulates*, reinforces*, relieves, reminds, removes*, reorients, replaces, resolves, restores, restricts, rouses, satisfies, sensitizes*, shapes*, sharpens*, signals, softens, stabilizes, stimulates, strains*, strengthens*, supports, sustains, sways, tempers, thwarts, transfers, transforms, translates*, transmits*, triggers, undermines*, unfolds*, weakens

Note that these and related terms are not references to mere statistical operations, mathematical functions or abstract universal laws. They are action words, verbs, explicit theoretical references to putatively causal generative mechanisms-things influencing other things, hypothesized psychological processesthat can exist only in concrete living individuals. References to such intraindividual processes figure prominently in the Introduction sections of all 39 articles, where they are drawn on to establish the theoretical rationale and justification for each study's research focus. We are told, for example, that the purpose of a study is to test "whether parents, siblings, and peers influence the development of relational aggression ... [and] whether relational aggression has reciprocal effects on these socialization agents" (Aizpitarte et al., 2019, p. 118), or to determine 


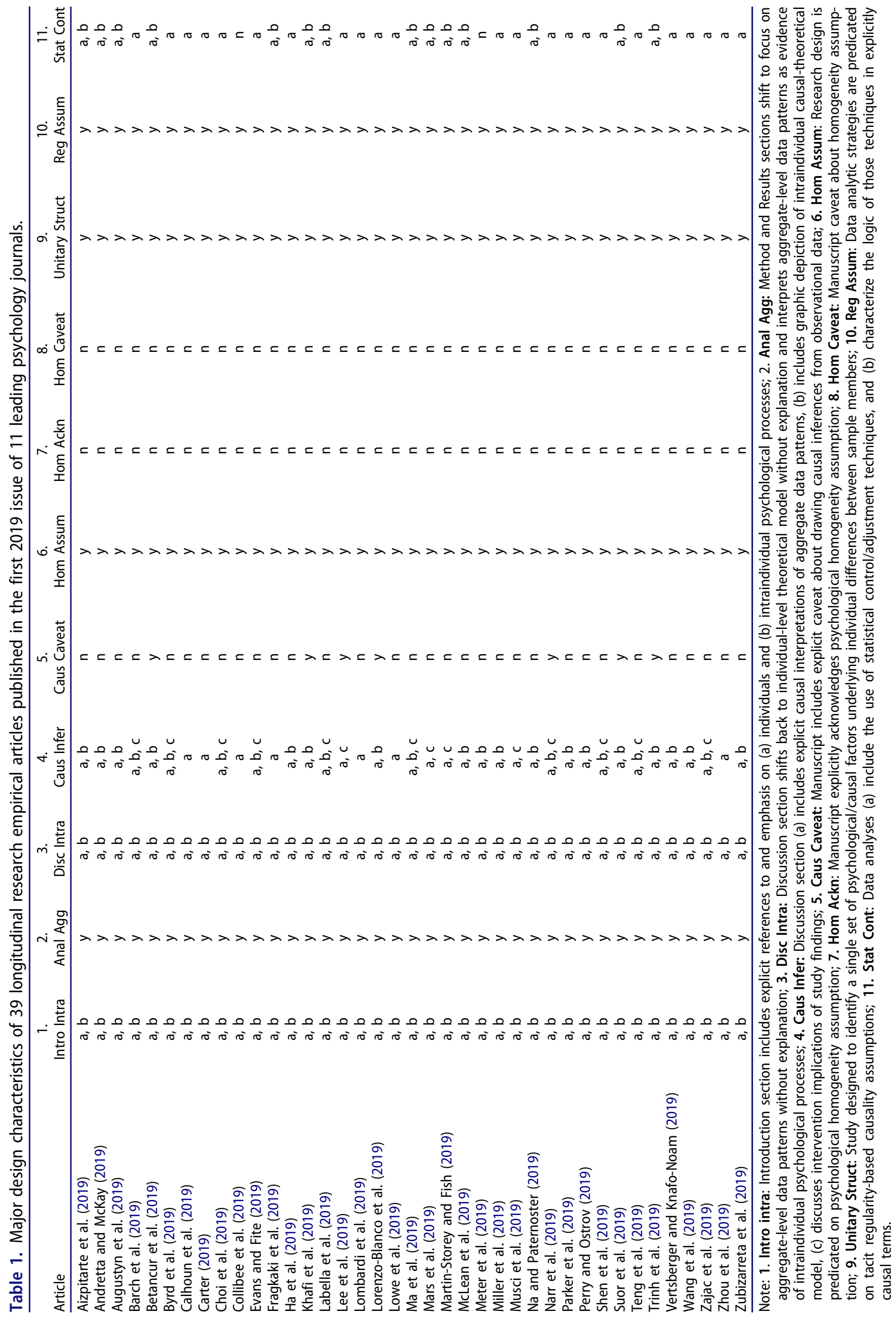


"whether higher quality [maternal caregiving behavior] would protect against ADHD risk conferred by higher levels of reactivity" (Miller et al., 2019, p. 45), or to examine "how multilevel processes contribute to delay of gratification outcomes within distinct profiles of children's temperamental reactivity" (Suor et al., 2019, p. 145), or "to explore the daily mediating mechanisms that might explain the longitudinal effect of parental cultural socialization on adolescents' private regard" (Wang et al., 2019, p. E20), or "to test the mediating role of postpartum depression between maternal childhood maltreatment and a cascade of negative child outcomes" (Choi et al., 2019, p. 144), or to "delineate how multilevel processes contribute to delay of gratification outcomes" (Suor et al., 2019, p. 345 ), or to "evaluate adulthood romantic relationship functioning as a potential mediator of parenting outcomes associated with childhood abuse and neglect" (Labella et al., 2019, p. 97), or to examine "whether these processes operate differentially based on the timing of maltreatment" (Augustyn et al., 2019, p. 57), or "to investigate both parent and child factors influencing parenting" (Vertsberger \& Knafo-Noam, 2019, p. 125), or to study "the impact of early trauma as an additional socialization context in the development of coercion in future romantic relationships" (Ha et al., 2019, p. 208).

\section{Aggregate-level empirical models}

In the Method and Results sections of all 39 articles, however, the unit of analysis shifts abruptly and without comment from a theoretical focus on psychological characteristics of individuals to an empirical focus on the statistical properties of an aggregate-level empirical model. Although the purpose of each study is to advance theoretical knowledge about the functioning of psychological processes within concrete individuals, the individual differences paradigm privileges aggregate-level data patterns as the only legitimate grounds for establishing such knowledge claims. The empirical question of interest is therefore not whether the individual-level theoretical model is reflected in the intraindividual psychological processes and functioning of particular sample members but whether it is consistent with the interindividual variance data structure of a statistical aggregate. Thus, the purpose of the data collection process is not to produce evidence about the concrete individuals of ultimate theoretical interest but rather to strip them of their individuality by disassembling each sample member into isolated parcels of information, the theoretical meaning and causal significance of which will be determined by computer algorithms on the basis of aggregate-level data patterns to which they contribute. Following a brief description of sampling strategies, subject recruitment procedures, and data collection processes, the concrete individual is left behind as the discussion turns to technical details of data reduction, score distributions, and estimates of the parameters of measurement and path models based on aggregated data. Results presentations are characteristically marked by a disciplined avoidance of explicit causal language, with aggregate-level data patterns typically described in the more modest, atheoretical statistical language of covariance structures, conditional dependencies, effect sizes, and the relative statistical contributions of specific variables to variance in the dependent variable(s) of interest. Nonetheless, it is manifestly evident that the investigators are using the aggregate-level empirical model as a proxy for the hypothesized intraindividual psychological processes of sample members (Danziger, 1985).

In the Discussion sections of all 39 articles, however, the unit analysis shifts again, seamlessly and without explanation, from the aggregate-level empirical model back to the individual-level theoretical model of the Introduction section. The linguistic landscape is no longer quantitative and statistical but once again qualitative and theoretical. Variables no longer merely predict and correlate as they did in the Method and Results sections. We are told now in the Discussion sections that they also influence and explain one another, as investigators interpret the aggregate-level data patterns as causal evidence of the intraindividual psychological processes that they never actually studied. In some cases, the causal inferences are direct and explicit. We are told in one report, for example, that the investigators "observed that the influence of socioeconomic status on children's delay of gratification was mediated by children's set-shifting at age 5 in the heightened reward reactivity and negative affectivity profile" (Suor et al., 2019, p. 355). In others we are told that "gender difference in sexual homophily was shaped more by friendship selection processes that upheld the sexual double standard" (Trinh et al., 2019, p. e142), or that "postpartum depression, especially when followed by recurrent maternal depression, plays a mediating role in the intergenerational transmission of maltreatment ... with downstream consequences for children's wellbeing" (Choi et al., 2019, p. 154), or that "early nurturing relationships with parents affect future partner relationships as far-reaching as into late life by 
promoting conflict resolution skills" (Ha et al., 2019, p. 212). In other cases, the causal inferences are elliptical rather than direct, implicit rather than explicit, tentative and qualified rather than certain and absolute. We are told, for example, that "the present study lends needed insight into childhood processes that may contribute to long-term psychological outcomes" (Zubizarreta et al., 2019, p. 241), or that results "may suggest that witnessing community violence simultaneously disrupts children's self-regulatory capacities ... and reinforces [their] aggressive behavior, resulting in increases in externalizing behavior problems" (Musci et al., 2019, p. 77), or that they "generally suggest that duration of unemployment across young adulthood had scarring effects on clinically significant mental health problems later in life for both genders" (Lee et al., 2019, p. 37). Regardless of variations in language and phrasing, though, it is clear from the context that we are being invited in all 39 Discussion sections to join the authors in concluding that the aggregate-level data patterns reveal something causally important about the intraindividual psychological processes of concrete, living individuals. More specifically, we are being asked to join them in presuming a priori that exactly the same psychological structures and processes functioned in exactly the same way within each individual sample member to produce their respective data points in the aggregate.

\section{The inferential passage from aggregates to individuals}

Notably absent from all 39 articles is an explicit acknowledgment of, let alone explanation for, this fluid shift from the individual-level theory to the aggregate-level empirical model and then back again. The entire process unfolds without comment or explanation as though it were self-evident that aggregate-level patterns of interindividual differences are straightforward reflections of the intraindividual psychological processes of sample members. But aggregates and individuals are qualitatively different entities (Danziger, 1985). Individuals are biological organisms with brains characterized by psychological structures and processes. Aggregates are statistical constructions of numerical data collected from and about individuals, constellations of data points characterized by numerical distributions and data structures that possess no inherent meaning or theoretical significance. Which is why aggregate-level, variable-based data patterns, correlates, and covariance structures do not automatically qualify as evidence about the psychological processes and causal structures of individuals.

The inferential passage from descriptions of aggregate-level data patterns to theoretical inferences about intraindividual psychological structures and processes is a narrow one that requires a scaffolding of assumptions about the comparability of aggregates and individuals to negotiate justifiably and successfully. Although these assumptions are highly interdependent and seldom invoked in isolation from one another, I tease them apart below in the service of demonstrating their embeddedness in the cross-level aggregateto-individual inferences of the Table 1 studies. Given that the psychological homogeneity assumption functions as a load-bearing support beam for this scaffolding it provides a natural starting point and frame of reference for examining the logical underpinnings of the individual differences methodology.

\section{Psychological homogeneity and the logic of sample-based inferences}

As illustrated in the Method and Results sections of all 39 Table 1 articles, the empirical focus of individual differences research is not the concrete individual of theoretical interest. Rather, it is an aggregate of data points reflecting quantitative differences between individuals whose psychological structures and processes are presumed a priori to have produced those data points in exactly the same way. There are compelling reasons to believe that most psychologists are unaware of their methodological reliance on the psychological homogeneity assumption and would have no difficulty explaining the manifold reasons why it can't be true (see How the individual differences paradigm perpetuates itself). Regardless of what may be going on in the minds of investigators, however, the psychological homogeneity assumption is implicitly invoked by the simple act of cross-level aggregate-toindividual inferences because it is the only condition under which the interindividual variance structure of aggregated data would be an accurate reflection of the intraindividual variance structure and hence psychological processes of each sample member. The logic and coherence of aggregate-to-individual inferences hinges decisively on the tacit assumption that individuals from whom the data are aggregated are interchangeable members of a single class whose data points are reflections of exactly the same underlying psychological processes (Bakan, 1966; Boker et al., 2009; Holland, 1986; Molenaar \& Ram, 2009; West et al., 2010; Xie, 2011). The individuality of particular 


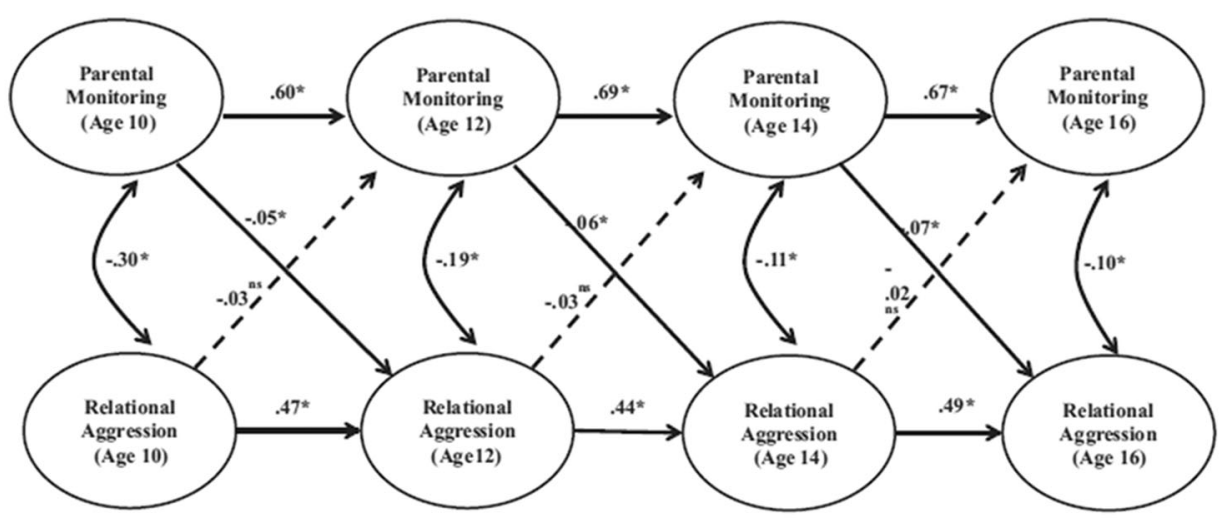

Figure 1. Cross-lagged panel model from (Aizpitarte et al. 2019, p. 121).

sample members within the individual differences framework "is deemed immaterial: the subjects are considered to be replications devoid of individuality" (Molenaar \& Ram, 2009, p. 256). Individuals are indispensable to the research process but only as conduits for information about the aggregate. The quantitative data points they contribute are used merely to construct a composite statistical model-an aggregatelevel digital portrait-of a hypothetical individual characterized by the single constellation of psychological structures and processes presumed to be responsible for the functioning of all sample members. Consider, for example, the Aizpitarte et al. (2019, p. 121) structural model duplicated in Figure 1. Based on aggregated data from a 6-year longitudinal study of 674 Mexican-origin youth, it depicts a cross-lagged panel model (with coefficients) of reciprocal causal relations between parental monitoring and children's relational aggression from ages 10 through 16 .

Predicated on the faulty assumption of psychological homogeneity (see The heterogeneity of psychological structures and processes), the logically implicit claim underlying this panel model is that it accurately reflects the intraindividual covariation structures that would have resulted on average from repeated assessments of each sample member over time at each level of each study variable.

\section{Exegesis: psychological vs. statistical homogeneity}

It should be clear at this point that psychological homogeneity is a substantive theoretical assumption of the individual differences methodology about the psychological structures and processes of concrete individuals and not a statistical assumption concerning the distributional properties of aggregated data. Although the two are often conflated, the distinction is a crucial one because many widely used statistical procedures are known to be quite robust to violations of distributional assumptions under a variety of conditions. Consequently, they are commonly viewed as idealizations that can be ignored with impunity or statistically "corrected" for many practical purposes. But theoretical interpretations of sample-based data are not robust to violations of the psychological homogeneity assumption. It is a rigid, indispensable requirement because it functions as the logically necessary connective tissue between individual-level theoretical models and aggregate-level empirical models on which the individual differences paradigm implicitly relies to justify aggregates as a proxy for individuals. Moreover, for reasons I explore in later discussion (see Statistical controls and iatrogenic effects) psychologically heterogeneous samples cannot be rendered homogeneous by statistical control procedures because all such statistical adjustment techniques also depend on their logic and justification on the same psychological homogeneity assumption.

\section{Corollaries of psychological homogeneity}

In addition to justifying aggregates as the object of empirical inquiry, the psychological homogeneity premise also licenses the scaffolding of corollary assumptions necessary to justify cross-level inferences from aggregate data patterns to intraindividual psychological structures and processes. These corollaries, which are reflected in the major design characteristics of all 39 studies summarized in Table 1, are but different methodological instantiations of the fundamental psychological homogeneity assumption on which the entire individual differences framework rests (see The surface and substrate of individual differences methodology). The tacit premise that individuals are homogeneous with respect to the psychological structures and processes underlying their overt functioning, for example, licenses the implicit assumption (corollary \#1) of all 39 studies that a single multivariate 
causal structure is sufficient to explain individual differences in the functioning of all sample members. Psychological homogeneity also licenses the tacit assumption (corollary \#2) of all 39 studies that each candidate variable under consideration either does or does not exert a causal influence on the outcome of interest and, if so, in exactly the same way for every sample member. That is, psychological homogeneity logically precludes the possibility that the same variable may be a causal influence for some sample members, a protective influence for others, a consequence of the outcome for others, and a non-causal spurious correlate of the outcome for yet others. It also, for the same reason, justifies the a priori assumption that the same causal factor influences the behavior of every sample member in exactly the same way. That is, it precludes the possibility of a causal factor that exerts a direct influence on the behavior of some sample members, an indirect influence on the behavior of others, and a bidirectional influence on the behavior of yet others, etc.

Psychological homogeneity is also a logically necessary precondition for the implicit assumption of all 39 studies that causes are reflected in patterns of regularities (e.g., contingent relations, covariations) with their effects (corollary \#3). This assumption is reflected in the explicit causal interpretations of covariations in all 39 studies, $72 \%$ of which also included graphical depictions of their causal models-typically with directional arrows and path coefficients, 38\% of which also elaborate on the implications of their causal conclusions for intervention efforts. We are told, for example, that the study findings "underscore the need for prevention efforts to include a community-wide strategy which implements interventions at multiple levels of the social ecology as well as a concerted effort to reduce community violence" (Musci et al., 2019 , p. 77), or that they "have significant implications for prevention and intervention programs designed to target youth at risk ... incorporating caregivers into intervention (particularly during adolescence) may also be warranted" (Byrd et al., 2019, pp. 372-373), or "highlight the need for intervention during the early elementary school years" (Evans \& Fite, 2019, p. 95), or "indicate a needed shift in service profiles for unemployed young people ... that not only facilitate reemployment but also address mental health needs to help them to cope with job loss" (Lee et al., 2019, p. 39), or underscore the "importance of distinguishing cognitive-emotional and physiological symptoms in the prevention and treatment of anxiety problems in young children" (Ma et al., 2019, p. 321), or "have direct implications for intervention and prevention ... and encourage the development and evaluation of programs aimed at eliminating the stigma associated with sexual minority status prior to adolescence" (Martin-Storey \& Fish, 2019, p. 77).

Tacit reliance on homogeneity-based correlationcause corollary is reflected also in the fact that $98 \%$ of the studies employed one or more statistical procedures to control for the disturbing influence of factors that would otherwise obscure the covariation patterns between and among variables of theoretical interest (corollary \#4). In $36 \%$ of these reports, statistical controls were characterized in explicitly causal terms. We learn in one report, for example, that the investigators "... examined the effects of each of the predictors separately controlling for the other two influences (e.g., testing the effect of parental monitoring on relational aggression controlling for the effects of sibling and peer influence) (Aizpitarte et al., 2019, p. 122), in another that " $\ldots$ our model controls for endogenous network processes that could inflate estimates of sexual debut status on friend selection" (Trinh et al., 2019, p. 138), and in another that the purpose was "... to minimize the confounding influence of variables related to our outcome of interest." (Martin-Story \& Fish, 2019, p. 78). Even in the absence of explicit causal characterizations such as these, however, the intention behind all such statistical correction procedures within the context of examining theoretical (vs. measurement and predictive) models is inherently causal in nature (Meehl, 1970, 1971). That is, their purpose is to remove the putatively causal influence of variables that could not be controlled experimentally (Freedman, 1987a, 1987b).

\section{The remarkable, unremarkable psychological homogeneity assumption}

\section{Contemporary literature}

One of the most remarkable things about the psychological homogeneity assumption is that it isn't considered remarkable at all in the literature of psychology. Literally. Although indispensable to the logic of the individual differences methodology, the psychological homogeneity assumption is rarely acknowledged in empirical reports (and never in the 39 articles in Table 1), let alone explained or justified. When the terms "homogeneous" or "homogeneity" appear at all in the empirical literature they are virtually always references to either demographic similarities of research subjects or the variance distributions of sample data (see Exegesis: psychological vs statistical homogeneity). This 
pattern of omission is also reflected in the Publication Manual of the American Psychological Association (APA) (APA, 2010), the official recommendations of the APA Task Force on Statistical Inference (Wilkinson et al., 1999), and the most recent recommendations of the APA Working Group on Quantitative Research Reporting Standards (Appelbaum et al., 2018). These publications offer guidance and recommendations on a wide range of methodological and statistical issues, including subject recruitment, inclusion and exclusion criteria, psychometric properties of instruments, sampling and statistical power calculations, statistical control procedures, homogeneity of variance, hypothesis testing, effect sizes, distinguishing between statistical and theoretical significance, and related issues. What these and other official guidance publications do not discuss, however, is anything remotely interpretable as an acknowledgment of or reference to, let alone justification for, assumption of psychological homogeneity.

There is nothing per se unusual about the common practice of relying on unstated background assumptions given that they enjoy a presumption of validity once accepted by a scientific community. What renders this particular omission both noteworthy and troubling, however, is that there is no evidence of an explicit justification for the psychological homogeneity assumption in the accumulated literature of psychology dating back to the early $20^{\text {th }}$ century. My brief look at the historical origins of the individual differences research tradition below reveals that the psychological homogeneity premise was adopted and incorporated into the methodological canons of psychological research not on the basis of an articulated conceptual rationale or theoretical justification, but rather by fiat. Not because there were compelling reasons for believing that it is true, but in spite of evidence that it is false because it was and remains a pragmatically and computationally convenient assumption.

\section{Historical literature}

The earliest explicit endorsement of the psychological homogeneity assumption in the literature of psychology is expressed in Edward L. Thorndike's famous axiom:

All intelligible differences are ultimately quantitative. The difference between any two individuals, if describable at all, is described by comparing the amounts which A possesses of various traits with the amounts which B possesses of the same traits (Thorndike, 1911, p. 6).
Several years later, Thorndike also advocated for a correlational approach to studying individual differences by explaining "What kind of individuals there will be, and what proportion there will be of each kind, is a result of the distribution of individuals in single traits and the correlations of the traits" (Thorndike, 1918, p. 148), and "The study of the facts and laws of individual differences enables us to apply these principles economically in the case of each individual whom we seek to influence" (Thorndike, 1918, p. 156). What Thorndike does not tell us in these and other publications, however, is why he believes so strongly that individuals are qualitatively the same. Let that sink in. The individual differences framework is in the formative stages of what will become and remains the dominant research paradigm in American psychology, and one of its leading, most vocal proponents, is merely asserting the foundational psychological homogeneity premise as a self-evident truth. No justification, no explanation, no rationale. Just a simple, unadorned, matter-of-fact assertion.

Almost 2 decades later, in her classic and influential differential psychology text, Anastasi also asserts, confidently and without explanation, that "Individual differences are quantitative rather than qualitative" (Anastasi, 1937, p. 29). And two years later, Gilliand \& Clark begin their text on the psychology of individual differences with the confident but unexplained statement "... the vast majority of differences with which we shall be concerned may be called differences in the amount and are accurately described as quantitative differences" (Gilliand \& Clark, 1939, p. 58).

Thorndike and his American contemporaries were not alone in their enthusiasm. Sir Cyril Burt, a prominent member of the so-called London School of Differential Psychology founded by Francis Galton and a future recipient of the American Psychological Association's E. L. Thorndike Career Achievement Award, expressed equal confidence in the validity of the psychological homogeneity premise:

\footnotetext{
There are, in fact, no such things as mental types; there are only mental tendencies. And the tendencies inherited are the same for all: the only differences are differences of amount. Men's minds are like their faces. Each at first seems unique. But closer scrutiny observes that the main component features are in everyone the same: all have two eyes, two ears, a mouth, a forehead, and a nose (Burt, 1927, p. 7)
}

\section{A well-tested compass}

Explicit comments about the psychological homogeneity assumption such as these are all the more 
remarkable because they are exceptions to the general rule in early American psychology-which was silence. Vocal skeptics from the beginning voiced criticisms of the individual differences methodology, its substitution of aggregates for individuals as the focus of research, and the presumed validity of the underlying homogeneity assumption. A natural science of psychology based on "the methods of Physical Science, duly extended and generalized" (Mill, 1843, p. 833), many argued, was inherently ill-suited to studying the inherently active, reactive, structurally complex, dynamic, and self-organizing nature of psychological and behavioral phenomena. As George Trumbull Ladd characterized it, the "so-called natural science of psychology" had "[sold its] birthright for a mess of pottage" (Ladd, 1892 , p. 51). But the majority of psychologists neither explicitly endorsed nor defended the methodology and its assumptions. They simply forged ahead with its deployment. For most in the majority, any weaknesses or inadequacies of the methodology were beside the point. Psychology was under mounting pressure to establish its legitimacy and practical value as a science in a deeply anti-metaphysical climate of positivism. Arguing a case for the uniqueness of psychological phenomena in the face of positivism's unquestioned authority at the time would accomplish little more than fanning the existing flames of doubt about whether a science of psychology was possible (Danziger, 1979, 1990).

It was William James, ever the pragmatist, who gave voice to what would become the majority opinion that eventually prevailed. James had devoted 12 years to writing his magisterial 1400 page "Principles of Psychology" from a positivist science perspective (James, 1890a, 1890b), hoping “... by treating Psychology like a natural science to help her become one" (James, 1892, p. 146). Two years following the release of Principles, in a no-holds-barred defense of his proposal, James conceded little ground in his response to George Trumbull Ladd's stinging and somewhat snarky "Psychology as a so-called Natural Science" critique (Ladd, 1892). About Ladd's charge that all such attempts to assimilate psychology as a natural science are misleading, James cheerfully acknowledged "... if there is any natural science in possession of a subject matter set apart from the others, it is psychology" (James, 1892, p. 147). But he also reminded readers that Ladd's own insistence on this uniqueness in the face of positivism's unchallenged authority ".. has proved a mere stumbling block to ... reviewers (of Ladd's own book)" (James, 1892, p. 150). "Why force it on their attention", James argued, "and merely perpetuate thereby a sort of wrangle from which physics and chemistry have long since emerged, and from which psychology, if left to the 'facts of experience' alone, promises so soon to escape?" (James, 1892, p. 150). Yes, as he had argued in the Principles, there are obvious limitations to the natural science model, but it was a necessary starting point, "the best mark of health that a science can show", and would have to serve as "a provisional halting place" for psychology until the eventual arrival of a more sophisticated "metaphysics alive to the weight of her task" (James, 1890a, p. vii).

James Rowland Angell offered similar assurances to critics attending his 1906 presidential address before the American Psychological Association. Echoing James' earlier assurances that this was a necessary but provisional commitment, Angell explained to his audience that

Psychology is still for a time at least to steer her own untroubled course. She is at most borrowing a welltested compass ... and she hopes by its aid to make her ports more speedily and more surely. If in use it prove treacherous and unreliable, it will of course go overboard (Angell, 1907, p. 73).

Opinions remain divided in the opening decades of the $21^{\text {st }}$ century about the wisdom and necessity of American psychology's initial embrace of the natural science model and the homogeneity-based individual differences methodology. But this much is not in dispute: On the question of whether and in what ways the science of psychology is "in possession of a subject matter set apart from the others" (James, 1892, p. 147) any earlier grounds for skepticism and debate have been eroded beyond the vanishing point over the past 100 years by a substantial body of uncontested evidence documenting the human nervous system's extraordinary plasticity and capacity for structural modifiability at every level of organization from molecular to molar (see Genetic underdetermination of psychological structures) and the resulting ubiquity of psychological heterogeneity as a defining characteristic of human functioning.

\section{The heterogeneity of psychological structures and processes}

\section{Psychology's terrible difficulties}

When Paul Meehl set pen to paper for his bravura Two Knights critique of the slow progress of so-called soft psychology in 1978, it took him only " 10 minutes of superficial thought $\ldots$ to easily come up with 20 features that make human psychology hard to 
scientize" (Meehl, 1978, p. 807). Beyond the inherent complexities introduced by polygenic heredity, powerful cultural influences, divergent causality, causal feedback loops, autocatalytic processes, unknown critical events and the like, Meehl notes, lie the enormous challenges of studying uniquely human events and powers:

there are several other human features that we do not share with chimpanzees, let alone sponges or boulders. Only man speculates about non-practical, theoretical matters; only man worships; only man systematically goes about seeking revenge, years later, for an injury done to him; only man carries on discussions about how to make decisions (Meehl, 1978, p. 816).

Meehl's 11-page discussion of these features was almost incidental to his animating methodological thesis, which was a punishing critique of statistical significance testing in psychology as an impoverished theory testing standard. Nonetheless, it stands as a masterful, classically Meehlian take on the distinguishing characteristics of psychological and behavioral phenomena that render them so inherently difficult to study. But Meehl's agenda was simply to communicate his awareness of "the terrible difficulties under which we work" (Meehl, 1978, p. 807). He therefore examines the 20 features in quasi-random order, each in relative isolation from the others, and makes no attempt to synthesize their commonalities and interrelatedness. Thus, it is easy to miss the pivotal significance of Meehl's two related observations concerning psychological heterogeneity that are classified separately on his list. Under the heading 4. Individual Differences, he observes that:

organisms differ not only with respect to the strengths of various dispositions, but, more common and more distressing for the researcher, they differ as to how their dispositions are shaped and organized. As a result, individual differences involved in 'mental chemistry' are tougher to deal with than, say, the fact that different elements have different atomic numbers or that elements with the same atomic number vary in atomic weights (Meehl, 1978, pp. 808-809).

Returning to the psychological heterogeneity theme several items later under heading 7. Idiographic Problem, he underscores the challenges it poses for scientific inquiry by observing:

the human personality-unless one approaches it with the postulate of impoverished reality-has in its content, structure, and, conceivably, even in individual differences as to some of its "laws," and very much in its origins, properties and relations that make the study of personality rather more similar to such disciplines as history, archeology (historical), geology, or the reconstruction of a criminal case from police evidence than the derivation of the molar gas laws from the kinetic theory of heat or the mechanisms of heredity from molecular biology (Meehl, 1978, p. 809).

It is noteworthy that Meehl here considers psychological heterogeneity to be a sufficiently obvious and non-controversial fact about "mental chemistry" that he feels no need to elaborate beyond these brief descriptions. His succinct characterizations of the individual differences and idiographic problems occupy only $5 \%$ of the text he devotes to the discussion of his 20 features. More significant for our purposes is that Meehl attaches no special significance to these problems relative to the other 18 on his list. They are simply features \#4 and \#7 on a list of 20 "intrinsic subject matter difficulties" (p. 806), each of which contributes additively to the cumulative challenges of "scientizing the mind" (p. 808). Equally noteworthy is that Meehl identifies these features exclusively as substantive problems in the first half of the article and has nothing to say about them when he turns his attention to methodological issues in the second half. The 20 features are left behind in the first half of the paper as a string of abstract, loosely connected "intrinsic subject matter difficulties", a catalogue of daunting, seemingly intractable complexities about which Meehl offers readers little more than the hand-wringing, the nothing-to-be-done observation that they constitute "the terrible difficulties under which we work" (Meehl, 1978, p. 807)-a topic to which I return in later discussion (see Methodological myopia and the riddle of Meehl's lament).

\section{A clarifying perspective}

In a commentary on Meehl's 20 features more than 2 decades later, his long-time friend and colleague David Lykken both complimented and complemented the original discussion by suggesting a clarifying perspective (Lykken, 2004):

I believe that these difficulties are more troublesome when one assumes, as a physicist might, that minds are structurally isomorphic, like hydrogen molecules or black holes, rather than realizing from the outset, as an engineer might, that minds differ both parametrically and structurally, so that some laws apply generally but many apply only to isomorphic subgroups of individual minds ... The mind consists of genetically-determined hardware and experientially-determined software (differing) from one from another in terms not only of their 
accumulated software but also in aspects of their genetic structure (Lykken, 2004, p. 54).

Indeed, if we pull back to a wide-angle view of Meehl's list through Lykken's structural heterogeneity lens, the particulars of the 20 features fade to ground and their common denominator emerges in sharp relief. Meehl is exactly right about the powerful shaping influences of culture on human behavior and about the brute fact that "human beings think and plan and intend, that if rats do so they do it at a much lower level, that sunflowers probably do not, and that stones certainly do not" (Meehl, 1978, p. 816). In calling our attention to the unrecognized methodological implications of psychological heterogeneity, however, Lykken actually understated his case. These distinctive characteristics of psychological phenomena are not merely more troublesome if one assumes that brains are structurally isomorphic. Psychological isomorphism would render them impossible! The 20 features on Meehl's list exist precisely and only because our brains are not isomorphic. If they were, humans would be incapable of producing advanced civilizations, cultures, and the institutions of science, technology, and education that are necessary preconditions for the existence of an article such as this. These defining characteristics of the world we live in, a world populated by psychologically heterogeneous individuals, are reflections of the human brain's designed capacities for ongoing use-dependent, experience-based, and experience-expectant modifications to its internal psychological structures within each individual's lifetime.

\section{Machines and minds}

It is customary, almost obligatory, in contemporary discussions about the human brain to characterize its design and functioning characteristics with reference to the inner workings of a digital computer. The computer analogy offers a powerful boot-strapping heuristic for thinking about the modifiability of psychological structures in terms of something we already understand. The hardware-software distinction, in particular, provides a natural, intuitively appealing template for conceptualizing how and in what sense the human brain translates inherited dispositions and unique experiences of individuals into qualitative differences in their internal psychological structures.

Like all good analogies, however, the digital computer metaphor also has its limits. Brains are biological entities, not electronic devices; their functioning characteristics were shaped by evolutionary selection pressures rather than intelligent design. And brains, unlike digital computers, have bodies. Or, more relevant for our purposes, bodies have brains. The distinction is an important one because the reason bodies have brains is also the reason why psychological heterogeneity is such a pervasive characteristic of human functioning. Thus, to establish a serviceable foundation for understanding why and how this is the case, I will set the computer metaphor aside temporarily, reach for different gear, and follow the path of biological evolution to an explanation.

\section{Natural functions}

The pen I am writing with has the physical characteristics of length, width, and rigidity that render it useful for a variety of everyday tasks - pointing at things, propping doors open, pressing buttons, scratching backs, cleaning mud from shoes, and, as astronaut Buzz Aldrin demonstrated, rescuing the Apollo 11 space mission from a near-disaster by deploying it to complete a faulty electrical circuit (Aldrin \& Abraham, 2010). Each of these uses can properly be called a function of pens, in the sense that they are among the numerous practical things that can be done with a pen. But none of these functions would be a correct answer to the question what is the function of a pen?, which is a question about the function(s) of pens that explain why they exist (Amundson \& Lauder, 1994; Cummins, 1975; Nagel, 1977; Neander, 1991; Wright, 1973). The correct answer, obviously, is that the function of pens is handwriting; a product of the human invention, the pen is intentionally designed for the specific purpose of delivering a smooth, controlled flow of ink to writing surfaces.

There is, of course, no goal or purpose behind the complex functioning designs of biological structures and processes. Rather, they are products of the Darwinian two-step process of genetic variation and natural selection, an iterative process of random genetic mutations and replication errors acted on by natural selection pressures across eons of evolutionary time (Darwin, 1859; Mayr, 1964). Those relatively few genetic changes that happen by chance to confer inclusive fitness advantages over others are more likely to be passed on to subsequent generations, increase in population frequency, and eventually become part of a species genome. While there is no creative hand behind natural selection pressures, they are nonetheless ruthlessly systematic in their effects, 
resulting in complex biological structures that are intricately organized and function as though they had been designed intentionally to enhance inclusive fitness. Thus, when biologists speak of the natural functions it is with reference to the beneficial effects for which they were naturally selected rather than intentionally designed. But the underlying logic is exactly the same. Natural and intentionally designed functions are logically equivalent in the sense that both are defined with reference to the causes of their design and functioning characteristics.

\section{Natural functions of hearts and minds}

Most biological structures, organs and systems of the human body contribute to inclusive fitness by performing highly specialized function-specific adaptive roles in the body's ability to exploit life-sustaining resources and characteristics of the physical environment (e.g., oxygen, food, water, sunlight, gravity, temperature) that were relatively stable within predictable parameters over vast expanses of evolutionary time. Consequently, their natural functions were fine-tuned by selection pressures for reliability and efficiency in performing their specialized adaptive roles under those conditions in ways that are completely determined by genetic code.

The heart, for example, was shaped by selection pressures to perform the unique natural function of pumping blood, maintaining circulation throughout the body, and responding adaptively and efficiently in this capacity to changing demands on the body in coordination with other body organs and systems. The evolutionary tradeoff for this efficiency, however, is inflexibility in the heart's structural and functioning design. It cannot modify the ways in which it accomplishes its pumping function; the heart cannot freelance by devising novel structures to improve pumping efficiency in response to evolutionary novel environmental conditions, and it is incapable of stepping in to perform the natural functions of other bodily organs. The structural components of the heart and their integrated performance characteristics contribute to pumping blood in ways that are completely determined by a genetic blueprint common to all members of the human species and can be modified only through subsequent selection pressures acting on random mutations and replication errors.

Other biological systems are characterized by higher degrees of functioning complexity and integration with numerous body structures and processes. The immune system, for example, has a designed capacity to recognize and destroy foreign cells never encountered during evolution, learn from these encounters, and to tailor its subsequent defensive responses accordingly (Barreiro \& Quintana-Murci, 2010; Kioussis \& Pachnis, 2009; Koslow et al., 1995; Laurent et al., 2017; Nakajima \& Morimoto, 2019; Yirmiya \& Goshen, 2011). This capacity, in turn, allows the immune system to recognize millions of different foreign cells and to synthesize matching secretions and cells capable of destroying each of them (Schlindler, 1985). These remarkable functioning feats are accomplished, however, through highly specialized, standardized, hierarchically organized molecular processes of recognition, synthesis, and response that are genetically determined (Wilson et al., 2014). Thus, the immune system, like the heart, pancreas, lungs, bowels, kidneys, and most other organs and systems of the body, is the biological equivalent of a function-specific machine, genetically coded to produce and maintain particular biological end states in particular ways under particular conditions.

\section{Genetic underdetermination of psychological structures}

The processes of phylogenetically older subcortical brain structures, including those involved in regulating and coordinating internal processes (e.g., respiration, heart rate, sleep, blood pressure, body temperature), are characterized by genetically coded, function-specific designs that are similar to those of other biological structures. At progressively higher levels of brain structure, however, lie hierarchically organized cortical areas of increasing complexity, interconnectedness, and functional design plasticity from which arise the human capacities for memory, language, consciousness, emotion, personality, motivation, intentional behavior, reflecting on the past, anticipating the future, etc. (Al-Shawaf et al., 2016; Bauernfeind \& Babbitt, 2019; Cosmides \& Tooby, 2013; Edelman, 1987, 1992; Frankenhuis, 2019; Lindenberger \& Lövdén, 2019; MacLean, 2016). These and other characteristics of psychological functioning were shaped over the course of evolution for adapting to characteristics of physical, social, and cultural environments that were highly unstable across and within generations.

Selection pressures, therefore, favored genetic changes that conferred greater plasticity in the brain's ability to draw flexibly on these higher-level capacities to meet constantly changing day-to-day, moment-tomoment adaptive demands. Thus, in contrast to hearts 
and livers, their functioning designs are genetically underdetermined, allowing them to continue evolving somatically (i.e., non-genetically) during ontogenetic time in response to each individual's environmental experiences (Dalton \& Bergenn, 2007; Edelman, 1987). The modifiable end states of psychological structures and processes, as it were, are subservient to the brain's genetic equivalent of a policy instruction: to interact with the environment in ways that maximize the body's inclusive fitness (Eccles, 1991). Moreover, the brain's ability to maintain this ultimate end state-by formulating, evaluating, selecting, implementing, and revising its behavioral strategies based on environmental contingencies-is critically dependent on this genetic underdetermination and experience-based modifiability.

The human brain at birth is the most underdeveloped, undifferentiated organ in the body, and undergoes rapid post-natal experience-expectant and experience-dependent organization and neural development throughout the first year of life (Bick \& Nelson, 2017; Cisneros-Franco et al., 2020; Lindenberger \& Lövdén, 2019; Linderkamp \& Linderkamp-Skoruppa, 2021; Perry et al., 1995; Tooley et al., 2021; Wigley et al., 2021). These early processes serve the crucial natural function of calibrating brain development and organization to local conditions by relying on guidance input from internal and external environmental cues (Greenough et al., 1987). Thus, the algorithms underlying these shaping processes are exquisitely sensitive during early brain development to the qualitative nature, frequency, intensity, and patterning of both internal and external environmental cues. Many developmental brain processes such as neuronal proliferation, migration, and differentiation also remain active throughout much of early childhood, during which massively overproduced neurons, synapses, and dendrites are subsequently pared back, modified, shaped, and selected by environmental experiences through what has been dubbed a form of "neural Darwinism" (Edelman, 1987). There is a substantial and growing body of evidence from the neurosciences, evolutionary biology, and nonhuman primate research for crucial periods in brain development during which certain types of environmental experience may have profound, enduring influences on important characteristics of the brain and nervous system functioning (Anda et al., 2006; Barlow, 2019; Bjorklund, 2018; Fox et al., 2010; Gottlieb, 1991, 2007; Harris et al., 2017; Lent \& Tovar-Moll, 2015; Lerner \& Overton, 2017; Lickliter \& Witherington, 2017; McLaughlin et al., 2019; Overton, 2013; Oyama, 2000;
West-Eberhard, 2003; Witherington \& Boom, 2019a, 2019b).

Once the initial functioning parameters of psychological structures and processes are established by the experience-expectant algorithms underlying early brain development and organization, they remain extensively open to experience-dependent adaptive modifications throughout the lifespan. Their genetic underdetermination allows the brain to draw flexibly on virtually limitless combinations of different psychological structures and processes to meet the adaptive behavioral demands of everyday life. Although the visible manifestations and adaptive advantages of this modifiability are self-evident, there are significant knowledge gaps in our understanding of the precise neural mechanisms and functioning principles through which they come about. For example, the simple fact that psychological structures and processes are emergent characteristics of brain functioning and do not instead arise from function-specific, anatomically distinct structures like the heart and liver, renders it far more difficult to establish bankable answers to questions about how they should be conceptualized, defined, and assessed. Despite a richly detailed theoretical literature on these topics, there is still little anyone can say with justifiable confidence about whether traditional distinctions between emotions, motivations, consciousness and the like are accurate reflections of nature carved at its joints or merely intuitively appealing fictions that are useful but fundamentally wrong and misleading in some deep sense. There is also considerable debate among contemporary theorists about whether the algorithms underlying psychological structures and processes are general-purpose guidance mechanisms or instead highly specialized, domain-specific neural circuits characterized by genetically fixed stimulus preferences, learning biases, and non-learned response dispositions. Everyone agrees that the brain would be incapable of functioning adaptively-and therefore could not have evolved-in the absence of heritable guidance mechanisms. Moreover, no one disputes the empirical evidence demonstrating that the processes underlying brain development and functioning appear guided by numerous stimulus preferences, learning biases, and non-learned response dispositions. Thus, the debate is not about whether, but only about the extent to which, in what ways, with what degrees of freedom, and how the functioning parameters of psychological processes are under the influence of heritable guidance mechanisms. 


\section{Biological complexity and degenerate brains}

Disagreements over particulars aside, however, there is no mystery or uncertainty about the well-documented design principle of biological degeneracy from which the functional capacities and experience-based modifiability of psychological structures and processes arise. In the literatures of pathological medicine, social Darwinism and eugenics, degeneracy is a negatively charged word that always refers to something bad (Mason, 2015). Within the nomenclature of the contemporary neurosciences, evolutionary biology, and related disciplines, however, degeneracy refers to a distinctly positive, adaptive design characteristic of complex biological systems (Maleszka et al., 2014; Mason, 2010, 2015; Tononi et al., 1999; Whitacre \& Bender, 2010).

In its most general form, degeneracy refers to the capacity of different (i.e., non-isomorphic) structural elements of a biological system to contribute to or perform the same function or generate the same effect (Edelman \& Gally, 2001; Price \& Friston, 2002). Unlike fully redundant backup structures, which are isomorphic and isofunctional, the capacities of nonisomorphic degenerate structures are multifunctional, capable of contributing to more than one functional outcome. Thus, degenerate systems are characterized by both many-to-one (degeneracy) and one-to-many (pluripotent) structure-function relations.

The human genome, for example, is an inherently degenerate system, as reflected in both the many-toone structure-function nature of polygenic traits and the one-to-many structure-function effects of pleiotropic genes (Frank, 2003; Whitacre, 2010; Whitacre \& Atamas, 2012). Degeneracy renders polygenic traits inherently more robust to mutational changes in any particular gene. It also permits the accumulation of non-deleterious cryptic genetic variation with latent potential for enhancing evolvability by facilitating a greater range of phenotypic variation in responding to the adaptive demands of changing environments (West-Eberhard, 2003). A particularly striking example of cryptic genetic variation-dubbed "the dark matter of biology" (Gibson \& Dworkin, 2004, p. 681) - is the Antennapedia mutation in Drosophila melanogaster flies. Depending on the environmental conditions to which it is exposed, the Antennapedia mutation can produce an extraordinary range of distinctly different phenotypes, ranging from near-perfect antennae in certain environments to near-perfect legs where the antennae would otherwise be in other environments (Gibson \& Reed, 2008).
Beyond these intragenomic-specific manifestations, degeneracy is a ubiquitous feature of biological complexity. It has been observed at all levels of biological organization and is recognized as the fundamental design principle underlying all complex biological systems, ranging from basic processes of thermoregulation, metabolism, respiratory control, and immune response to the more complex processes underlying the development, organization, and experience-based modifiability of the brain. The adaptive advantages of biological degeneracy-and the reasons it was favored by evolutionary selection pressures-are twofold. First, as illustrated in the case of pleiotropy and polygenic traits, degeneracy renders biological systems inherently less fragile and more robust to environmental perturbations. In addition to protecting against cascading failures propagated by single-function loss, degeneracy ensures that the loss or compromise of any particular functional component will have a limited impact on the overall functional integrity of the system due to the overlapping functionality of its multiple components (Whitacre \& Bender, 2010). Second, whereas fully redundant, unifunctional backup structures contribute only to robustness, the multifunctional capacities of degenerate structures also greatly expand the flexibility and capabilities of biological systems. The functioning capacities of the immune system, for example, are critically dependent on its ability to generate an extensive degenerative population of antigen-recognition sites (Edelman \& Gally, 2001). Restoration of sensorimotor and cognitive functions following neurological damage also stems from the inherent degeneracy of underlying neural networks (Price \& Friston, 2002).

The many-to-one/one-to-many structure-function signature of biological degeneracy is also a defining characteristic of human psychological functioning and behavior. Although the concept of degenerate design hasn't yet worked its way into the standard lexicon of psychology, it is the unifying explanatory principle underlying the more familiar concepts of equifinality and multifinality, which are widely recognized characteristics of psychological functioning and behavior (Richters, 1997). Equifinality, which stems from the many-to-one structure-function dimension of degeneracy, is reflected in the wide-ranging capacity of individuals to leverage different psychological structures and processes to accomplish the same behavioral outcome. Multifinality, which stems from the one-tomany structure-function (i.e., pluripotentiality) dimension of degeneracy, is reflected in the capacity of individuals to leverage the same psychological structures 
and processes to accomplish multiply different behavioral outcomes.

Terminological preferences aside, the unmistakable fingerprints of degeneracy are everywhere around us. Concisely catalogued in Meehl's 20 features list, the tell-tale secretions of degeneracy are reflected in everything we feel, prefer, contemplate, aspire to, plan for, decide against, act on, reconsider, regret, object to, endorse, fight for, run away from, love, hate, embrace, reject, exaggerate, repress, deny and dream about across the course of our lives. A masterpiece of degenerate design, the human brain is unique among biological structures in terms of both its extraordinary range of functioning capabilities and its unparalleled degrees of freedom in deploying them due to their genetic underdetermination and inherent degeneracy.

\section{The ubiquity of psychological heterogeneity}

These well-established design and functioning characteristics of the human brain suggest a rather obvious explanation for the notable absence of a full-throated defense of the psychological homogeneity assumption in the accumulated literature of American psychology: No one believes it. Nor is it imaginable on what rational, theoretical, or empirical grounds any contemporary psychologist would feel comfortable defending it. Psychological heterogeneity is such a ubiquitous, defining, widely recognized characteristic of human functioning that it is simply taken for granted as a self-evident truth in the social discourse and behavior of everyday life and presumed by virtually all psychological theories. We recognize intuitively that the mere fact that someone donates generously to charities implies nothing necessarily about why they donate-the causes or motivations underlying their actions. We understand that some people donate strictly for tax write-off purposes, others to enhance their reputations in the community (e.g., John Gotti), others because they are deeply committed to a charity's objectives (e.g., Bill Gates), or more generally to the principle of helping others (equifinality). And, for the same reason, we understand that not everyone who is charitably disposed toward others contributes generously to charities. Depending on a matrix of other internal and external factors, a charitable disposition toward others may be acted on through volunteer activities, teaching, elective office, simply behaving compassionately toward others, or may not be acted on at all due to competing internal-psychological or external factors (multifinality).

\section{Causal heterogeneity and inus conditions}

A useful framework for thinking about the methodological implications of psychological heterogeneity is provided by Mackie's concept of causally sufficient conditions in the naturalistic world (Mackie, 1974). In the study of closed systems in physics, theories frequently can be refined to the point of being able to specify conditions that are both necessary and sufficient for the occurrence of a phenomenon (Elsasser, 1981). Many effects in the natural world, however, can be produced by a variety of qualitatively different conditions that are unnecessary but sufficient for their occurrence. A building fire, for example, can be caused by any number of qualitatively different conditions-arson, an electrical short-circuit, a carelessly discarded cigarette, a bolt of lightning, etc. Each of these conditions is itself unnecessary but sufficient for producing a building fire under certain circumstances (e.g., the presence of combustible material, oxygen, etc.). Moreover, each sufficient condition consists of a qualitatively different constellation of elements, each of which is alone causally insufficient but contributes non-redundantly to the causal efficacy of that unnecessary but sufficient (inus) condition. The elements of the arson inus condition, for example, might include a flammable liquid, a lighted match, and a person intending to burn the building down. Individually, each of these elements is causally insufficient by itself for producing a fire; it is only collectively that they constitute an inus condition for an arson fire. Thus, they are insufficient, non-redundant components of an unnecessary but sufficient (inus) condition (i.e., arson) for producing a building fire.

The complexity of studying inus conditions underlying human functioning, of course, is that the same factors may play qualitatively different causal roles across different inus conditions for the same overt functioning pattern. Consider, for example, commonly studied correlates of children's antisocial behavior such as impulsivity, marital discord, parenting deficits, deviant peers, school failure and the like. It requires little effort to imagine clinically and theoretically plausible circumstances under which each of these factors may be a causal influence in one or more inus conditions for antisocial behavior, a consequence in others, a protective influence in others and a spurious correlate in yet others. For example, there are a variety of potential inus conditions that might plausibly give rise to a pattern of antisocial behavior in childhood. One condition might be a criminogenic neighborhood and/or family environment in which antisocial behavior is modeled, expected, and/or 
rewarded by major influences in a child's life. This is certainly a plausible model to consider in 21 st century America, wherein many major cities the allure of drug-related crime is ever-present, and where gangs virtually control the social commerce and economic life of many neighborhoods. Another might include an inherited or acquired diathesis for impulsivity in conjunction with poor self-esteem, a violent home environment and/or community, and minimal support or nurturance from caregivers. It is not difficult to imagine that inus conditions for antisocial behavior such as these might differ qualitatively from those giving rise to antisocial behavior among children raised in a mainstream culture characterized by fundamentally different influences, socialization pressures, and opportunities. Moreover, even within each of these different subcultures, there may be children whose antisocial behavior was initiated and/or is sustained primarily by the need for money to support drug or alcohol dependence, an expression of anger against parents or adult authority figures, or a method of attention-seeking. Persistent antisocial behavior in other children may stem primarily from inherited or acquired deficits in nervous system functioning that translate into problems of impulse control or difficulties learning from experience either absent or irrespective of these other conditions. For others, the inus condition may be positive personal characteristics such as high intelligence and resourcefulness in conjunction with conditions of poverty, poor parent monitoring, and/or a criminogenic neighborhood. And yet others for whom none of these factors is relevant may have been socialized into deviant value systems and/or may be coping defensively in hostile, dangerous environments (Richters \& Cicchetti, 1993a, 1993b).

\section{Psychological and causal heterogeneity in vivo: a ground-level view of 9 hypothetical cases}

To understand the methodological implications of psychological heterogeneity, consider the following hypothetical scenarios. Eric does moderately well in school but doesn't think he stacks up to his highachieving older siblings, develops low self-esteem, and becomes highly susceptible to the influence of deviant peers, resulting in an escalating pattern of antisocial behavior problems. Eric's twin brother Ed also does moderately well in school and realizes he doesn't measure up to the accomplishments of his older siblings. Unlike Eric, however, Ed maintains his selfesteem by exceling at nonacademic activities such as student government and sports, thereby establishing his own high-achievement status within the family.

Tom has a mild frontal lobe deficit which translates into concentration problems, poor grades, and problems of impulsivity. Angry and resentful when his parents insist that he is simply not trying hard enough, Tom retaliates by getting into trouble with deviant peers. Tom's brother Ted also has the same frontal lobe deficits, suffers similar problems of concentration, poor grades, and impulsivity, and becomes similarly angry and resentful when his parents suggest he isn't trying hard enough. A close-up witness to the negative consequences of his brother Tom's retaliation, however, Ted is determined not to follow the same path and instead develops active coping strategies to overcome his functioning deficits, leading to significant improvements in his school performance.

Rob's anxiety over his parents' marital discord gives rise to deteriorating school performance, friendship problems, and low self-esteem, which results in a temporary suspension of marital hostilities as his parents work together to help him. This, in turn, unconsciously reinforces Rob's tendency to precipitate new crises periodically through delinquent behavior to restore marital harmony. Rob's younger brother Ron exhibits a similar anxiety-related deterioration in school performance due to his parents' marital discord. But Ron also feels increasingly isolated and alienated within the family as his parents devote more and more attention to Rob's problems, leading him to seek emotionally supportive relationships with deviant peers by joining in their antisocial behavior. Rob's older brother Russ is also anxious about his parents' marital problems, but he minimizes those anxieties by diverting his attention away from their problems through an intensive, narrow-minded focus on schoolwork, resulting in superior rather than deteriorating school performance like his brother Rob.

Dave, by all accounts, was a well-adjusted child with excellent school grades until the onset of his parents' marital difficulties last year. Over time, as their occasional marital spats evolved into more frequent heated exchanges, verbal insults, and unresolved conflicts, so also did Dave's feelings of emotional instability, isolation, and hostility, which he began acting on through increasingly impulsive, risk-taking, and antisocial behavior. Initially, a consequence of his parent's marital discord, Dave's antisocial behavior also became a contributory bidirectional cause, with Dave's antisocial behavior taking an increasingly heavy toll on their marriage, which in turn took an increasingly heavy toll on Dave's antisocial behavior 
problems. Dave's brother Don has also suffered emotionally from his parents' marital problems, but with an admixture of guilt because Don knows that those problems originated in his antisocial behavior 12 months earlier when his parents began arguing over alleged deficiencies in child-rearing practices responsible for his behavior. To relieve his guilt feelings, Don eventually turns away from his antisocial behavior and focuses his energy on schoolwork, resulting in a track record of superior academic performance.

The parents of 9 boys score similarly high on marital discord but it is a causal factor in Rob's and Ron's antisocial behavior-though in different ways, a bidirectional influence in Dave's case, a consequence of Tom's antisocial behavior, and causally irrelevant to Eric's antisocial behavior. In Don's case, marital discord was initially a consequence of his antisocial behavior and later served as a primary motivating factor in his recovery and academic success. Similarly, although Tom, Rob, and Eric all suffer from low selfesteem, it is a causal factor for antisocial behavior only in Eric's case; Tom and Rob develop low selfesteem because of how others treat them in response to their antisocial behavior. And, in Ed's case, low self-esteem served as a positive motivating factor behind the esteem-enhancing nonacademic successes that established his parity with siblings. Deviant peer influence was a causal factor in the antisocial behavior of Eric and Tom. In Ted's case, however, exposure to the negative consequences of brother Tom's antisocial behavior served as a protective factor of sorts-a disincentive for antisocial behavior, motivating him to actively avoid his brother's fate by pursuing positive goals.

No one knows how many qualitatively different psychological-causal structures-inus conditions-such as these might be responsible for the population of antisocial children at any given time. Nor for that matter is there any empirical basis for confidence that Eric, Dave, Tom or the others necessarily exemplifies any of them. But the particulars here don't matter. The essential point is that no one seriously doubts that these kinds of qualitative differences exist. Or believes that children are structurally homogeneous with respect to the psychological processes underlying the etiology and maintenance of their antisocial behavior. Or doubts that the population of antisocial children at any given time is characterized by an asyet-unknown number of qualitatively different causal structures (e.g., constellations of internal-psychological and external causal factors). No one seriously believes that events and experiences have fixed, inherent causal properties, independent of the psychological makeup and circumstances of the individuals experiencing them-that the meaning, salience, and causal impact potential of events and experiences are qualitatively the same across individuals regardless of differences in their genetic endowments, their experiential histories, their resulting internal psychological structures and processes, and their current circumstances and anticipated futures. But the individual differences methodology on which psychologists rely to conceptualize, interpret, and guide their empirical research, however, depends for its coherence and justification on the logically implicit premise that all of these things are true, which returns us to the methodological implications of psychological heterogeneity.

\section{Methodological implications of psychological heterogeneity}

When Clark Hull introduced his automated correlation calculating the machine in 1925, he was almost giddy with enthusiasm about the virtues and seemingly unlimited potential of his new invention (Hull, 1925). Designed to "eliminate the drudgery and persistent errors" (Hull, 1925, p. 522) of manually calculating correlation coefficients, Hull's invention promised the next best thing to a free lunch: a convenient lunch.

while the machine is doing its various calculations ... the attention of the operator is not required by the machine at all ... the writer on several occasions has started the machine on a long and difficult column of computations, locked the laboratory and gone out to lunch ... Upon his return the computation was found completed ... the machine having stopped itself at the conclusion of the operation. (Hull, 1925, p. 530)

In the halcyon days of the mid-1920s, it was difficult for Hull and his contemporaries to anticipate any downside to the obvious virtues of automated statistical calculations. But that was before the mid- $20^{\text {th }}$ century digital revolution fueled the development of increasingly sophisticated statistical techniques, gave rise to the widespread availability of computerized statistical packages, and gradually revealed the hidden costs of Hull's convenient lunch. By eliminating the drudgery of step-by-step manual computations, computerized statistics have also insulated psychologists from the concrete realities of their original raw data:

the cookbook user of partial correlation is not, so to speak, forced by the working formalism (unless he refreshes himself on the derivation [of residuals]) to 
look the counterfactual problem squarely in the face when asking himself how this final derived number is to be textually interpreted. (Meehl, 1970, p. 395)

A closely related cost is that the inherently abstract concepts and language of contemporary multivariate statistics lend " $\ldots$ an air of unchallengeable sanctity to conclusions that would otherwise be subjected to the most intense scrutiny" (Cliff, 1983, p. 116) and create the seductive illusion that we have somehow solved, risen above, or successfully negotiated the correlation-cause question at the simple bivariate level. We have not.

Beneath the surface of the colliders, mediators, disturbance terms, and backdoor/frontdoor adjustments of structural-equation models, path analysis and other approaches to causal modeling lies a simple matrix of zero-order correlations, the causal interpretations of which hinge decisively on the psychological homogeneity assumption and its corollaries. And because the addition of more variables and interaction terms does nothing to alter this stubborn reality, the methodological challenges it poses for the individual differences methodology can be understood most easily by considering the simple bivariate case.

\section{Homogeneity at work: interpreting a bivariate correlation}

So here is a multivariate data set from a longitudinal study of family factors associated with the development of antisocial behavior in childhood. The study was initiated in the service of exploring the relative goodness-of-fit between the aggregate-level covariance structure and various alternative causal models of direct and indirect paths of influence between several family factors and antisocial behavior. Our focus here, however, is on the more modest question of what to make of a single component of the covariation matrix: a zero-order correlation of .34 between marital discord and antisocial behavior. Because any theoretical interpretation of the covariation matrix will necessarily entail an inference about the causal/noncausal status of each variable, our question is what causalinferential possibilities exist for this particular .34 correlation. To simplify our task, we will adopt Meehl's pedagogical advice to: "Assume you had the parameter; what would you know, and how confidently?" (Meehl, 1990a, p. 117). We will presume as well that the observed .34 correlation is not an artifact of either statistical outliers or shared methods variance. Thus, we are concerned exclusively with identifying the data-generating process responsible for the .34 correlation between marital discord and antisocial behavior.

Relying on the individual differences psychological homogeneity assumption, there are at least 7 causal possibilities: (1) marital discord exerts a direct causal influence on antisocial behavior (e.g., Ron) and/or (2) an indirect causal influence through its effect on another variable that is causal for antisocial behavior; (3) antisocial behavior exerts a direct causal influence on marital discord (e.g., Tom) and/or (4) an indirect causal influence through its effect on another variable that is causal for marital discord; (5) marital discord and antisocial behavior exert a direct bidirectional influence on one another (e.g., Dave) and/or (6) an indirect bidirectional influence through their effects on other variables that are causal for each; (7) marital discord and antisocial behavior are causally unrelated, the correlation is spurious, an artifact of the influence of one or more so-called third variables on each (e.g., Eric). Setting aside for the moment additional possibilities that might arise from suppressor variables, the control of which would reveal a negative association, there are at least 7 possible causal conditions that are consistent with, and potentially explanatory of, the .34 correlation between marital discord and antisocial behavior. How to proceed?

This is where the psychological homogeneity assumption gets to work. It begins the heavy lifting by licensing the corollary \#1 assumption (see Incredible utility thesis) that these 7 possibilities are also mutually exclusive conditions. That is, they are genuinely competing for explanations for the .34 correlation in the sense that only one can be correct. If, as the individual differences methodology presumes, sample members are psychologically homogeneous, it cannot be the case that marital discord is a causal influence on antisocial behavior for some sample members, a consequence for others, and non-causal for yet others. Nor, on the homogeneity assumption, can marital discord exert a direct causal influence on antisocial behavior for some sample members and an indirect influence for others through its effect on another variable that is itself causal for antisocial behavior. The homogeneity assumption also forecloses the possibility of an indirect influence of marital discord that is mediated through its effect on variable A for some sample members and through its effect on a non-A variable for others. Marital discord either is or is not a causal factor for the antisocial behavior of all sample members. And, if it is, the particulars of the causal path(s) - whether direct, indirect, or both-must be qualitatively the same for all sample members as well. 


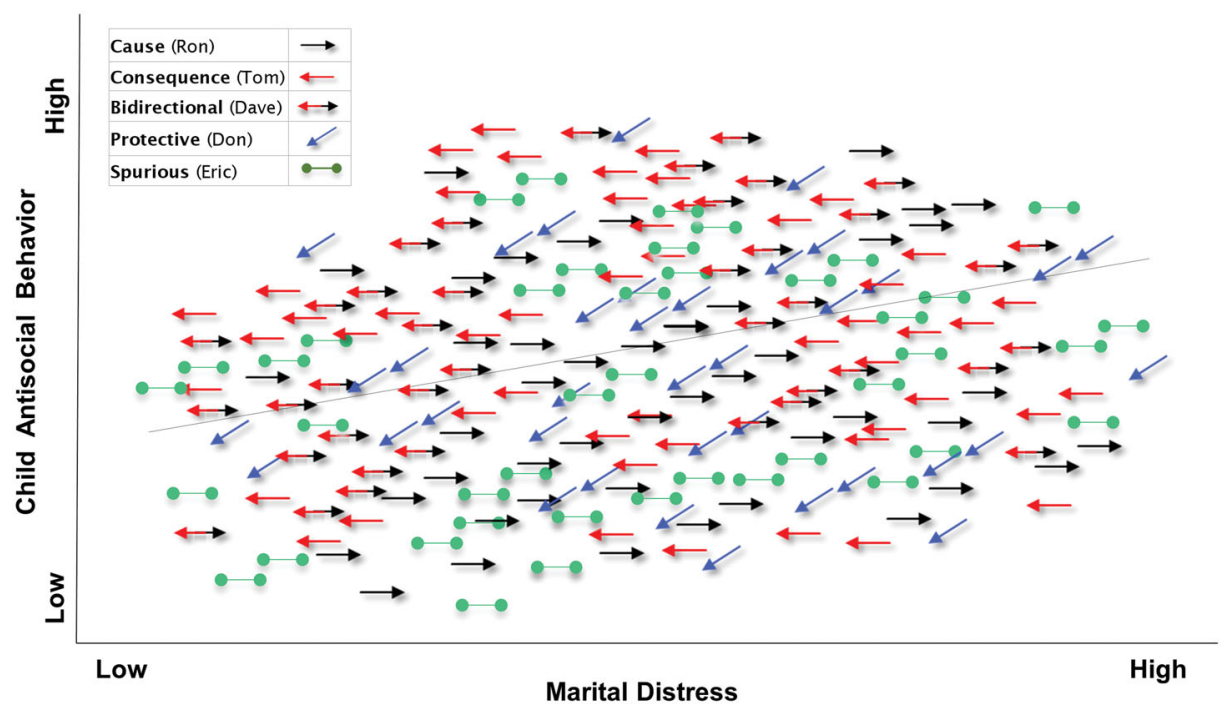

Figure 2. Hypothetical bivariate scatter plot for a .34 correlation between marital discord and antisocial behavior based on a heterogeneous sample of Ron-, Tom-, Dave-, Don-, and Eric-like cases (see section Psychological and causal heterogeneity in vivo: A ground level view of 9 hypothetical cases).

In addition to warranting the search for a single causal explanation for our .34 correlation, the homogeneity assumption also licenses the necessary corollary assumptions 2-4 (see Incredible utility thesis) for a straightforward comparative evaluation of the 7 competing explanations in the service of identifying what Rogosa aptly termed "the causal winner" (Rogosa, 1980, p. 245). To evaluate the possibility that the correlation is spurious, for example, we need only calculate the partial correlation between marital discord and antisocial behavior, controlling statistically for the putatively causal influence of the suspected confounding variable(s). Similarly, to examine the possibility of a so-called reverse causal influence of antisocial behavior on marital discord or a bidirectional influence between the two, we would turn to a cross-lag panel analysis of the patterning, magnitude, and directional sign of the correlation over multiple time points.

In the canonical case, of course, our attention would not be focused on the causal possibilities for a single bivariate correlation, but rather on a multivariate causal model of often-complex paths of direct and indirect influence between independent and dependent variables. Moreover, as the number of variables under consideration increases, so also does the number of potentially competing causal possibilities. Regardless of the number and complexity of possible conditions, though, the logic and algebra underlying their evaluation remain the same. On the assumption of sample homogeneity, each condition can be translated into a corresponding causal model specification and examined against the others for its relative goodness-of-fit merits as a causal explanation for the data-generating processes underlying the observed covariation matrix.

\section{Homogeneity on leave: interpreting a bivariate correlation}

Returning to the .34 interpretation question without the aid of the homogeneity assumption places us on a radically different inferential landscape. We are now at base camp on the slopes of psychological heterogeneity with inadequate methodological gear for the climb. By checking psychological homogeneity at the door, we also necessarily checked its corollary \#1 assumption that our 7 causal possibilities are competing, mutually exclusive explanations for the .34 correlation. Thus, we now confront the prospect that they may instead be mutually compatible explanations. Compatible in the sense that all 7 structures may be an accurate characterization of the causal or noncausal role of marital discord for different subsets of sample members. As depicted in the Figure 2 scatter plot, the .34 correlation may instead be a statistical artifact, a theoretically uninterpretable residue of multiple, qualitatively different causal structures.

In the face of this possibility, it is irrelevant whether the aggregate-level covariation structure is more consistent with a Tom-like or Rob-like or Davelike or Eric-like causal model. There are innumerable plausible conditions under which statistical artifacts arising from unrecognized sample heterogeneity such 
as this could easily inflate, attenuate, mask, or completely engulf aggregate-level evidence of a theoretically important causal influence of marital discord on antisocial behavior that holds for only a subset of sample members. Moreover, artifacts stemming from unrecognized heterogeneity can just as easily give rise to an illusory .34 correlation in the absence of a causal influence of marital discord on antisocial behavior for even a single sample member.

The inferential challenges of interpreting our .34 correlation in the face of unknown sample heterogeneity are further compounded by the limited tools available for engaging them. When we checked our homogeneity assumption at the door, we also perforce forfeited any legitimate claim to corollaries 2-4 (see Incredible utility thesis) on which we normally rely to grapple with complex cause-and-effect questions. If sample homogeneity is no longer a bankable assumption, neither are the "conveniences for calculation" afforded by its corollaries that would otherwise serve as reliable algebraic guides through the causal thicket. In a world populated by heterogeneous individualsthe world we live in-variables do not and can not have fixed, invariant, inherent causal properties (corollary \#2). Nor in such a world are aggregate-level regularities between independent and dependent variables either valid or reliable clues to the presence or absence of causal influences (corollary \#3). It is also a world in which statistical control procedures do not, and can not under most conditions, allow us to see through the disturbing influences of presumed confounding variables for a clearer view of the true association and potential causal nexus between variables of theoretical interest (corollary \#4).

\section{Statistical controls and iatrogenic effects}

Am I overstating the methodological implications of psychological heterogeneity? Surely, there must be some way to leverage statistical controls, semi-partial correlations and the like to establish at least an initial foothold for unscrambling causes in a heterogeneous sample. Isn't there? The answer lies in a more granular look at the logic and algebraic mechanics of statistical control adjustments. The motive behind their usage is almost always a straightforward, scientifically compelling question: we are interested in whether an observed $x-y$ correlation reflects a causal nexus between the two or instead reflects a spurious association due to the confounding influence of variable $z$ on both. Given that we are passive observers of correlations served up by nature, our question is a counterfactual one: what would be the correlation between $x$ and $y$ if we did have experimental control over the putative influence of $z$ ? The statistical control answer to this counterfactual amounts to a quantitative doover of sorts, an algebraic Mulligan, a statistical upgrade from observational data to an "as-if-byexperiment" (Freedman, 1987a, p. 103) causal inference. Since we were unable to manipulate or block the suspected confounding influence experimentally, we attempt to remove it statistically-hence, the origin and seductively misleading meaning of 'control' in the analysis of observational data.

Although statistical controls are a mainstay of psychological research, it remains a matter of debate among statisticians whether most observational data sets are capable of meeting the exacting technical requirements necessary for the successful removal of a so-called third variable confounding influence. Distilled to their essence, those requirements amount to the homogeneity assumption and corollaries 1-4. Under these idealized, quixotic conditions, (a) all sample members are qualitatively the same-differ quantitatively but not qualitatively-with respect to the theory-relevant psychological structures and processes responsible for their overt functioning, (b) the datagenerating process underlying quantitative differences between them is a unitary causal structure common to all sample members, (c) each candidate variable under consideration either is or is not a causally relevant element of that structure, and therefore (d) the zeroorder correlation between $x$ and $y$ either is or is not an artifact of the joint influence of candidate confounder $z$ on both variables. Under these-and only these-conditions we simply bootstrap ourselves to an "as if by experiment" answer by computing the partial correlation between $x$ and $y$, controlling for $z$. That is, we reexamine the $x-y$ relationship after subtracting the suspected influence of $z$ from both sets of scores. The question is important, the rationale behind the statistical adjustment is sound, the math is straightforward, and the resulting partial correlation is a defensible, bankable answer, as long as the quixotic assumptions hold.

But consider now what happens when we apply this same statistical adjustment to the heterogeneous sample of Ron-, Tom-, Dave-, Don-, and Eric-like cases depicted in the Figure 2 scatter plot, where $x$ and $y$ are represented, respectively, by marital discord and antisocial behavior. Since the $x-y$ relationship is spurious only for the subsample of Eric-like cases, the correct answer to our $z$-as-confounder question is the $z$-corrected partial $x-y$ correlation based exclusively on data points from Eric-like cases. The problem, of 
course, is that the numbers don't remember where they came from and the matrix algebra doesn't care. For computational purposes, the algorithm is blind to qualitative distinctions between Ron-, Tom-, Dave-, Don-, and Eric-like cases; they are interchangeable members of a single class; the unit of analysis for statistical and inferential purposes is the sample itself. Thus, the partial $x-y$ correlation controlling for $z$ will be based on the covariance structure of the entire sample, such that identical pairs of $x y$ scores will result in identical residuals, regardless of which sample members contributed them. Inevitably, this will result in two related but distinguishable kinds of errors. First, because both the zero-order and $z$-corrected partial $x-y$ correlations will be based on the entire sample, the analysis will necessarily either under- or over-correct the true partial $x-y$ correlation for all Eric-like cases, and in unpredictable ways. Second, for the remainder of the sample-all nonEric-like cases-we know with equal certainty that the analysis will be removing an effect of $z$ that isn't there, that wasn't there to begin with! Thus, in an effort to remove a putative distorting influence from the original data set we have unwittingly introduced our own. In other words, we are now a causal factor in the data-generating process behind the 'corrected' covariation matrix we are attempting to understand. Given the unknown heterogeneity particulars of the sample, we have no way of knowing whether our statistical intervention introduced systematic bias of some sort or noise into the sample data. As I noted earlier, however, it doesn't really matter because sample-level covariations based on heterogeneous samples are both uninterpretable and irrelevant.

It should be redundantly clear from the exercises above that psychological homogeneity is not an innocent, simplifying assumption, the kind that can be discarded or swapped out for another in the face of suspected psychological heterogeneity. Sample members either are or are not psychologically homogenous with respect to the theoretical/causal structure(s) under consideration in a particular study. If they aren't, no psychometric correction procedure or statistical algorithm is capable of rendering them isomorphic. These quantitative strategies can transform the distributional properties of aggregated data. But they can't alter the heterogeneous data-generating psychological structures and processes from which those data patterns arise. Proceeding on the homogeneity assumption and its corollaries in pursuit of causal knowledge about inherently heterogeneous psychological phenomena is a prescription for methodological and statistical misadventures. Samples of unknown heterogeneity are a breeding ground for illusory causal inferences and faulty theoretical claims when they are examined using homogeneity-based data analytic strategies. Even worse, the resulting inferential errors are rendered inherently undetectable by data analytic strategies that are themselves predicated on the same faulty assumptions from which the errors arise.

\section{Homogeneity on leave: exploratory clustering strategies}

It warrants emphasizing that the inadequacies and dangers of sample-based approaches to causal and theoretical inference just reviewed do not reflect intrinsic weaknesses or inadequacies of quantitative, statistical methods. Rather, they are due entirely to a fundamental mismatch between the homogeneity assumptions of sample-based multivariate statistics and the inherently heterogeneous nature of psychological and behavioral phenomena. This distinction is important because not all statistical methods are predicated on the homogeneity assumption and its corollaries. There are a variety of exploratory techniques such as latent class clustering, taxonomic methods, and person-based data analytic strategies that are designed specifically for the task of identifying homogeneous clusters or sub-types of individuals within presumably heterogeneous samples (Brennan, 2016; Haslam et al., 2012; Meehl, 1992a, 1995; Miettunen et al., 2016). Thus, returning the heterogeneity slope metaphor, it is natural to consider whether analytic strategies such as these might be capable of giving us a leg up, as it were, by lowering the angle of ascent.

Although developed and employed for a wide variety of different purposes, the common denominator of such clustering strategies is their computational power for disaggregating heterogeneous samples into clusters of individuals whose intraindividual variability patterns are more similar to one another than to those classified into other clusters. Thus, on the assumption that qualitatively different causal structures will give rise to detectably different overt functioning patterns, the appeal of clustering strategies lies in their potential for identifying subgroups of sample members whose data patterns are at least suggestive of such structures. But there's a catch to the heuristic potential of algorithmic search strategies, and it's a big one. Clustering algorithms are mathematically elegant and can be tailored and fine-tuned for extraordinary sensitivity in detecting similarities and differences in complex data 
patterns. But these algorithms are not magic. They can't recognize patterns that aren't there. They can't circumvent or otherwise violate Freedman's law of conservation of rabbits: "If you want to pull a rabbit out of the hat, you have to put a rabbit into the hat" (Freedman, 1997, p. 182).

What kind of data, then, would be required to capture a causal rabbit and place it in the data analytic hat for later retrieval? The answer, of course, will depend on the particulars of the theoretical-causal structure under consideration. As a general matter, however, the ideal conditions would be a study design and data collection strategy formulated on the basis of well-developed, theoretically grounded insights or hypotheses about the number and nature of qualitatively different causal structures responsible for a particular syndrome or overt functioning pattern in the population of interest. Each causal structure in turn would have to be elaborated in sufficient detail to specify how individuals characterized by each variant would be identifiable and distinguishable from the others on the basis of detectably different constellations of causally relevant information reflected in the history, nature and patterning of their overt functioning. Assuming that these hypothesized causal variants actually exist in the population, are adequately represented in a study sample, and that the corresponding theory-relevant information is captured with sufficient fidelity during the data collection process, the resulting data set should be comfortably located in the deep end of the cluster analytic promise pool. Again, if the data collection process succeeded in placing the rabbits in the hat, any number of clustering algorithms would have little difficulty pulling them back out.

To imagine such a data set, however, is to imagine something of a paradox: a data set the existence of which presupposes a level of theoretical knowledge that would obviate the need to produce it, and without which it could not exist. Either we possess the necessary theoretical insights to produce such a data set, in which case there would be no need to generate it for exploratory purposes, or we don't, in which case we would be incapable of generating it. There would be nothing paradoxical, obviously, about generating such a data set for quasi-confirmatory purposes and/ or for estimating the population prevalence and incidence of these variants. But our focus here is exclusively on the potential of post-hoc exploratory analyses of psychologically heterogeneous data sets, and the practical point is a simple one: there is probably an inverse relationship between the need for post-hoc exploratory analyses and the knowledge requirements for generating the necessary data set for harnessing their potential.

\section{Rabbit stew and individual differences}

Freedman's conservation of rabbits law draws attention to two easily and often overlooked facts about the statistical issues just examined. First, as illustrated in the example of paradoxical clustering, the success of data analytic rabbit-retrieval efforts at the conclusion of a rabbit hunt hinges decisively on how well the causal rabbit was conceptualized, measured and thus captured during the earlier data collection process. Second, the homogeneity assumption and its corollaries don't magically appear out of thin air and come into play only during the analysis and interpretation of data. Rather, they are bedrock assumptions of the individual differences paradigm itself and are baked into all earlier phases of the research process. In prior sections we found them reflected in the focus on samples and populations as the object of study (see Psychological homogeneity and the logic of sample-based inferences), in cross-level inferences from aggregate-level data patterns to conclusions about individual-level psychological processes (see The inferential passage from aggregates to individuals), and in the tacit logic underlying multivariate data-analytic strategies and as-if-by-experiment statistical controls (see Homogeneity at work: interpreting a bivariate correlation). Turning now to the data collection phase of the research process, we see them reflected in kinds of information collected from each sample member, how that information is captured, and-equally telling-the kinds of information left behind.

\section{Catching the quantitative rabbit}

The methods, measures, and assessment strategies of the individual differences data collection process are most easily-and perhaps only-understood as integrated capture components of what amounts to a quantitative causal rabbit hunt. As we saw in the methodological assay of individual differences studies summarized in Table 1 (see The plumbing and wiring of individual differences methodology), causal rabbits take on two distinctly different forms across the pages of empirical articles. In the Introduction and Discussion sections, causal rabbits are typically described in the familiar psychological language and concepts of theoretical discourse. Almost always, the rabbit is characterized with reference to hypothesized generative mechanisms and intraindividual 
psychological processes through which external and/or internal-psychological factors cause or influence the overt functioning of concrete individuals. The individual differences paradigm, however, privileges aggregates as the only legitimate grounds for causal knowledge. Thus, to be suitable for empirical inquiry, hypothesized causal rabbits must be temporarily transformed into a quantitative form compatible with the ontological assumptions underlying the methodology and the epistemological assumptions underlying its justification (i.e., hypothesis testing) standards.

The objectives and parameters of the data collection process are a joint function of two foundational assumptions of the individual differences paradigm. The first, of course, is the familiar assumption of psychological homogeneity, which licenses the corollary \#2 assumption that a hypothesized causal rabbit, if it exists, will-must-influence the functioning of each sample member in exactly the same way. The second, however, is a methodological conceit that causal rabbits are elusive, evade capture, and cannot be caught at the individual level. Due to the complex disturbing effects of factors catalogued on Meehl's 20 features list (see Psychology's terrible difficulties) the behavior of any particular individual, according to the canons of the paradigm, is too noisy and variable across situations and time to serve as a trustworthy guide to the presence or absence of causal rabbits. When data from a large enough number of individuals are pooled, however, it follows that these person-specific particulars will cancel each other out, rendering the causes they share in common visible in the form of aggregate-level statistical regularities.

There is also a more subtle but equally powerful reason the paradigm discourages attempts to identify causal rabbits on a case-by-case basis at the individual level: a deep distrust of human judgment, abiding faith in the purity and objectivity of quantitative data, and reverential confidence in the precision and power of statistical algorithms. Thus, even under ideal conditions of visibility, any attempt to capture a causal rabbit at the individual level would necessarily risk the inevitable errors, subjectivity, and other foibles of human judgment that "lie in ambush and surprise not only the active observer but also the contemplative one who appears safe from all passion" (Goethe, 1792, $\mathrm{p}, 14)$. As a safeguard against this contamination, the paradigm delegates all responsibilities for identifying and interpreting causal rabbits to the errorless, valuefree precision of matrix algebra-the algorithms praised by $19^{\text {th }}$-century statisticians for their mathematical ability to "[average] away everything contingent, accidental, inexplicable, and personal, and [leaving] only large-scale regularities" (Porter, 1996, p. 86).

The day-to-day business of gathering information that will be used to identify the rabbit necessarily entails the risks of this contamination. Numbers, obviously, only become numbers through the imperfect evaluative judgments of humans. Opportunities for error and bias are minimized, however, by enforcing strict adherence to standardized practices, routinized procedures, and carefully circumscribed information gathering protocols during the data collection process. Think factory assembly line, not clinic. A carefully organized sequence of Likert-scaled questionnaires, structured interviews, and validated test batteries. The objective is collecting data, not evaluating information. Those collecting the data will be respectful but dispassionate. Their interactions with research subjects will reflect disciplined detachment, not conversational engagement. Nothing personal, strictly business. The paradigm is interested in aggregates, not individuals; patterns of data, not the particulars of persons. Individuals are indispensable to the process, but only as conduits for information about the aggregate. And to collect this information, as Royal Astronomer John Pond stated it bluntly, "I want indefatigable, hardworking, and, above all, obedient drudges ... of superior order ... who will be contented to pass half their day in using their hands and eyes in the mechanical art of observing" (Babbage, 1830, p. 64). Better to restrict their efforts to capturing isolated parcels of disembodied rabbit-relevant information, each parcel carefully carved from the connective tissue linking it to others, stripped of context, and sterilized through the rigors of standardization, to ensure objective data points with sharp quantitative edges but no inherent meaning. The theoretical meaning of the numbers, the "really real" meaning (Daston, 1995, p. 10), will come later through the conduit of multivariate statistical analysis and modeling. With this ultimate objective in mind, the goal of the data collection process is to gather enough rabbitrelevant information to capture it in the covariance structure-to place it in the data analytic hat for later retrieval and interpretation. Not to worry if any theoretically important signal is left behind on the carving table along with the systematic bias and noise; it can be restored later by recombining data points into more recognizable and interpretable structures.

\section{Methodological virtues and vises}

The almost antiseptic nature of the data collection process has been a frequent complaint of those not 
steeped in the individual differences tradition. Critics dating back to the early decades of the 20th century have characterized the process variously as "mechanical, atomistic, additive, cut and dried, artificial, unreal, arbitrary, incomplete, dead, pedantic, fractionated, trivial, forced, static, superficial, rigid, sterile, academic, oversimplified, pseudoscientific, and blind." (Meehl, 1954, p. 4). The common denominator of most complaints has been a focus on the surface characteristics of the data collection process and its obvious disparities with the more contextualized and nuanced ways we elicit information from and about people in our everyday lives. Throughout this long history there also has been considerable puzzlement among critics about why their grievances and prescriptive remedies have gained so little traction within the mainstream. It is not evidence of sloth that psychologists have been so slow on the uptake. Rather, it reflects a long-standing impasse between the paradigm's critics and its adherents. An impasse born of the incommensurable lenses through which they view the same methodological practices and procedures. What critics see as artificial, mechanical, and barren information gathering, individual differences researchers see as objective and scientifically rigorous data collection. What critics dismiss as atomistic data, adherents admire as nature carved at its joints. Where researchers see unpolished gems, critics see only folderol. Butchered phenomena through one lens, carefully trimmed data the other. Blind obedience from one perspective; principled commitment the other. Tribalism from one, shared tradition the other. Common sense/idiosyncrasy, sound judgment/subjective bias, flexible/unreliable. The list of honorific/ pejorative pairings is almost endless. And beside the point, if not pointless.

There is nothing intrinsically wrong or right about the methods, measures, and mechanics of the individual differences paradigm in any absolute sense. Nor is there anything inherently compelling or obviously inadequate about any of the recommended alternatives. The dimensions of strength, power, efficiency, effectiveness, heuristic value, utility, potency, and validity are not intrinsic properties of methods. Whether and to what extent any particular method can be accurately characterized as possessing these virtues is entirely a matter of the specific purpose(s) for which it is used-a matter of goodness-of-fit between the functioning characteristics and capacities of the method on the one hand, and the demand characteristics of the phenomena or purpose for which it used on the other. Calipers are perfectly fine precision instruments for measuring wrist diameter and body fat. Not so much for measuring personality or intelligence.

The individual differences methodology is not a loosely connected set of design strategies, research methods, and analytic techniques. It is a methodological instantiation of the psychological homogeneity assumption and its corollaries-a highly integrated, tightly interwoven, internally consistent closed system of assumptions and methods predicated on the logical positivist philosophy and model of science. By prosecuting the surface characteristics of the data collection process rather than the faulty premises from which they arise, critics have misplaced the blame and ceded the only legitimate grounds for meaningful dialog about methodological issues. Their failure to gain traction within the mainstream isn't a problem of rhetoric, but physics. No ground, no traction. If the psychological homogeneity assumption and its corollaries are true, it follows that quantitative differences between individuals are reflections of common underlying causes, that aggregates are suitable proxies for individuals, and that it is possible to identify the causes of individual psychological functioning and behavior through statistical modeling of aggregate data patterns. But they can't be, they're not, they aren't, it isn't.

\section{How the individual differences paradigm perpetuates itself}

If the individual differences paradigm is predicated on demonstrably faulty assumptions about psychological and behavioral phenomena that render it inherently incapable of identifying their causes, why does it remain the coin of the realm for observational research in mainstream psychology? Why wasn't it abandoned long ago for a paradigm untethered to these assumptions, a methodology capable of shouldering the complex methodological challenges imposed by the structurally, functionally, causally heterogeneous nature of psychological phenomena? The short answer is that (1) psychologists are unaware of the paradigm's underlying assumptions and (2) because of this unawareness they also have no way of knowing that the paradigm is intrinsically incapable of yielding the causal knowledge they seek. Evidence of this unawareness is most clearly and unambiguously reflected in the fact that individual differences researchers formulate and interpret their research on the basis of a psychological homogeneity assumption and corollaries that are contradicted by the evidence 
of their own senses, invalidated by a substantial body of uncontested scientific research and theory, and that they don't believe!

We know psychologists don't actually believe that individuals are psychologically homogeneous because they tell us as much in the opening and closing pages of their empirical reports. As I illustrated earlier (see The plumbing and wiring of individual differences methodology) the animating theoretical questions behind the lion's share of individual differences research concern dynamic psychological processes and influences that would be impossible if individuals were psychologically isomorphic, and are intelligible only on the assumption that individuals are psychologically heterogeneous, that their internal psychological structures and processes are extensively modifiable by experience. Given that these explicit theoretical commitments per force imply a rejection of the psychological homogeneity premise-and, by extension, its corollaries-it is difficult to interpret psychologists' use of the individual differences methodology as anything other than a reflection of their unawareness of its reliance on these same assumptions.

This short answer, however, begs a far more important question: Why, after more than 100 years, do mainstream psychologists continue to be unaware of the paradigm's faulty assumptions? A review of contemporary psychological literature reveals widespread dissatisfaction within and outside the ranks of psychology with the limited theoretical progress of individual differences research, general agreement with David Lykken's late $20^{\text {th }}$ century assessment that "Psychology isn't doing very well as a scientific discipline ... something seems to be wrong somewhere" (Lykken, 1991, p. 4), and a considerable amount of head-scratching about what exactly that "something" is and how to proceed. Why, then, hasn't this dissatisfaction and uncertainty lead naturally to an awareness, scrutiny, and rejection of the faulty assumptions responsible for these failures? How has the paradigm's faulty homogeneity-corollaries scaffolding managed to fly under the radar and escape scrutiny for so long as the root cause of psychology's manifold problems as a science?

\section{The self-cloaking gravitational pull of psychological homogeneity and its corollaries}

The answer, in a nutshell, is that the individual differences methodology weaponizes psychological homogeneity and its corollaries into a self-cloaking, self-perpetuating paradigm flaw by relying on them as the de facto reference standard for evaluating their own merits. An inevitable consequence of this methodological self-dealing is a near-perfect paradigm flaw that renders itself invisible while exerting a powerful, unrecognized, undermining gravitational pull on individual differences research by bending major design decisions, data analytic strategies, and theoretical interpretations of research findings back in its own direction. My purpose in what follows is to explain how this self-perpetuating dynamic plays out, why it is so difficult to recognize without deliberate effort, and why attempts to conceptualize psychology's scientific problems and their solutions have failed to reach escape velocity from the paradigm's gravitational pull. To establish a serviceable foundation for this analysis I begin with a brief look at the basic general anatomy of scientific research programs, the privileged status afforded to foundational, so-called hard core assumptions like psychology's psychological homogeneity premise and its corollaries, and the natural, normatively rational reluctance of scientific communities to question their hard cores.

\section{Paradigmatic blindness and its virtues}

Consensus, compromise, and conformity do not spring immediately to mind when most people think about science. The popularized image is one of pioneering spirit, resistance to dogma, unfettered independence, and resistance to conventions. In reality, however, science is an inherently conservative enterprise, devoted largely to puzzle-solving activities, the objectives, parameters, and tools of which are determined in advance by the assumptions, priorities, and methodological conventions of ongoing research traditions or paradigms. No paradigm is perfect, and none is capable of identifying let alone successfully answering all the questions relevant to a given domain of inquiry. Historical studies, however, have shown that the most effective long-term strategy for achieving scientific progress is to turn a blind eye to the shortcomings of a paradigm and focus instead on exploiting its assets, the presumed heuristic virtues for which it was adopted, however limited those virtues may be (Kuhn, 1970). This exploitation in turn requires the disciplined willingness and commitment of a scientific community to suppress questions and concerns about the limitations of a paradigm until there is a reasonable basis for believing that its heuristic potential has been fully exploited. The continuity, coherence, and progress potential of scientific communities, in fact, 
hinges decisively on this commitment. So decisively that scientists are socialized by training and practice to grant the presumptive validity of their paradigm as a starting point for inquiry, and to formulate their research programs in accordance with its established priorities and methodological conventions. This is why individual differences researchers, as Kuhn observed of scientists more generally,

talk easily and well about the particular individual hypotheses that underlie a concrete piece of current research, they are little better than laymen at characterizing the established bases of their field, its legitimate problems and methods. If they have learned such abstractions at all, they show it mainly through their ability to do successful research. That ability can, however, be understood without recourse to hypothetical rules of the game (Kuhn, 1970, p. 47)

\section{Hard core privileges and protective belts}

It is a reflection of this same conservative commitment that psychological homogeneity and its corollaries enjoy the privileged status of Lakatosian "hard core" assumptions of the individual differences paradigm (Lakatos, 1980, p. 48). Privileged in the sense that hard core assumptions are so foundational and indispensable to the research activities of a scientific community that they are tenaciously shielded from scrutiny and refutation by a positive heuristic and "protective belt" of auxiliary hypotheses designed to bear the brunt of empirical and theoretical failures (Lakatos, 1980, p. 49). When confronted with theoretically unexpected empirical results, the modus tollens arrow is automatically deflected away from the privileged hard core and directed instead to a vast protective belt of modifiable, replaceable auxiliaries anchored to the hard core. If the study data don't square with theoretical expectations perhaps the fault lies in some aspect of the research design, methods, and/or measures. Maybe the theoretical constructs are poorly conceptualized, well conceptualized but poorly operationalized, or well operationalized but poorly measured-a problem of psychometric unreliability. Or maybe the failure stems from a sampling issue resulting in a restricted quantitative range of theoretically important variables. And if adjustments to methods-related auxiliaries don't bring the data into better alignment with the theoretical model, maybe something is wrong with the theory itself. Perhaps the theoretical model is framed too broadly, too narrowly, or with insufficient nuance or specificity. These few examples should suffice to explain why, once a set of assumptions or premises are incorporated into a scientific community's hard core, they are exceptionally difficult to rout because the protective belt provides an almost limitless supply of alternatives to the conclusion that they should be deserted.

As historical studies by Kuhn and others have shown, this conservative strategy has paid handsome dividends in the established sciences by protecting them against the perils of premature paradigm abandonment. The rub, of course, is that American psychology's adherence to this same conservative, normatively successful strategy has perpetuated its continuing embrace of the individual differences paradigm well beyond its use-by date, long past the point where there is any rational, theoretical or empirical basis for its justification. By relying on a scientific standard predicated on the same faulty assumptions from which the inadequacies of its methods arise, psychology deprived itself of the self-correcting feedback mechanisms of normal science and replaced them with a self-perpetuating paradigmatic scotoma that is inherently incapable of discriminating successfully between psychological facts and methodological artifacts, real and illusory phenomena, unitary causal structures and causal debris resulting from the inclusion of qualitatively different individuals in the same sample.

\section{The surface and substrate of individual differences methodology}

The process through which this self-perpetuating dynamic plays out arises from and is sustained by reciprocal, mutually reinforcing interdependencies between the paradigm's discovery and justification practices-those related to the capture and identification phases (respectively) of the quantitative rabbit hunt (see Rabbit stew and individual differences). An important upshot of my earlier reverse engineering analysis (see The plumbing and wiring of individual differences methodology) is that the individual differences paradigm is not the methodology itself. Rather, it is the hard core psychological homogeneity assumption and corollaries scaffolding from which the methodology arises and by which it is constrained. The scaffolding is logically prior to and determinative of the methodology. Thus, once the scaffolding is in place, the paradigm's discovery and justification processes necessarily take the form they do on the methodological surface within a narrow set of parameters imposed by the scaffolding.

Individual differences researchers, however, look naturally through the homogeneity-corollaries 
scaffolding and see only the methodology itself. Thus, with the pesky flawed assumptions hidden from view, what remains on the surface are the internally consistent, interdependent discovery practices and justification standards to which they give rise. Interdependent in the sense that a researcher's decisions during the discovery phase-about the essential nature of psychological phenomena, the kinds of questions worth pursuing, how those questions are framed, the most appropriate study design, subject population, research methods, data collection strategies, and analytic techniques for addressing those questions-will automatically and necessarily be formulated in anticipation of the logic, standards, and criteria by which study results will be interpreted and evaluated during the subsequent justification phase. If asked by a newly minted graduate student to explain the individual differences paradigm, most psychologists would have little difficulty crafting a perfectly rational explanation very much along the lines of my earlier characterization (see Rabbit stew and individual differences), but formulated entirely on the methodological surface with reference to the internal logic of the methodology: It would most likely begin with an explanation of the basic statistical rationale behind the paradigm's privileging of aggregates over individuals as the object of inquiry. This rationale, in turn, would serve as a foundation for explaining the necessity of quantitative theory evaluation criteria as well as the focus of discovery activities on collecting enough theory-relevant quantitative information about the psychological and behavioral functioning of individual sample members to allow for the identification of common underlying causes in aggregate-level data patterns during the justification phase. This explanation would most likely make sense to the graduate student because the paradigm's ground rules of discovery and justification do make sense when explained with reference to each other in this way. But only if the explanation remains on the methodological surface and only if the graduate student doesn't ask an obvious question about the man behind the curtain: yes, I understand the internal consistency and coherence of the methodology's discovery and justification processes; but what would necessarily have to be true of psychological and behavioral phenomena for this methodology to have any reasonable chance of identifying their underlying causes?

If voiced at all by an aspiring graduate student early in training the tacit assumptions question is unlikely to be pressed very hard for the same reason that questioning the legitimacy of the United States constitution isn't a winning strategy for those seeking U. S. citizenship. But for those already steeped in the tradition, this question is unlikely even to occur. As participants in an ongoing research tradition, each new generation of psychologists is socialized to take up where others left off, building on their accomplishments, assuming without question the foundational integrity of the paradigm and the capacity of its methodology to yield the theoretical and causal insights they seek. The individual differences methodology to them is just that. Not the methodological embodiment of corrigible ontological and epistemological assumptions, but an interwoven set of guiding principles, methodological imperatives, and tools for gathering and interpreting the theoretical meaning of data. A theory-neutral, self-contained, free-standing methodology, untethered to presuppositions and sufficiently unencumbered by foundational premises to be almost infinitely capable of being stretched to address even the most complex causal or theoretical questions with enough tinkering.

\section{How to diagnose a paradigmatic scotoma}

The thing about blind spots (scotomas) is that they're so difficult to see. Every normal human has a small anatomical blind spot in each eye due to the absence of photoreceptor cells where the optic nerve and blood vessels pass through the retinal wall. Although both scotomas are always there in front of our noses, we typically can't see them when using binocular vision because the overlapping visual fields of the eyes compensate for each other's blind spots. With both eyes open, each blind spot effectively renders the other invisible. With either eye closed, however, you can diagnose the blind spot in the other by following a simple exercise: Close your left eye, stare at the letter $\mathbf{R}$ below with your right eye, and slowly move the page toward you until the letter $\mathbf{L}$ disappears when it reaches your blind spot.

$\mathbf{R}$ $\mathbf{L}$

The paradigmatic scotoma that blinds researchers to the homogeneity assumption and corollaries can be understood and diagnosed similarly. Because the paradigm's ground rules of discovery and justification are reflections of the same flawed assumptions their complementary inadequacies are mutually compatible. Thus, when both sets of ground rules are included in a researcher's conceptual field of vision, neither appears flawed because the inadequacies of each mask, enable, and in so doing perpetuate the inadequacies of the other. As in the case of the visual scotoma, 
however, when either set of ground rules is excluded from the conceptual field of vision the inadequacies of the other are immediately apparent. With one conceptual eye closed to either side of the discovery/justification equation, we are confronted immediately with our hypothetical graduate student's tacit assumptions question: What would have to be true of psychological and behavioral phenomena for the methodology to have any reasonable chance of identifying their underlying causes? The answer, as we've seen, is inescapable. Like the elegant, intricate inner workings of Mr. Crowley's free energy device (see The incredible utility of perpetual motion), the paradigm's discovery and justification processes are internally consistent, logically related, seamlessly integrated, and for this reason the methodology appears intuitively plausible on the surface. But only on the surface because, like Mr. Crowley's device, this ground-level plausibility is an illusion that rests on tacit assumptions that cannot be true. Moreover, it is an illusion sustained by a paradigmatic scotoma of its own creation.

\section{Methodological myopia and the riddle of Meehl's lament}

The evidence and consequences of psychology's paradigmatic scotoma are writ large in its protracted struggle for scientific surefootedness. With psychological homogeneity and its corollaries out of view and off the table for consideration, psychologists from the beginning have approached issues of methodology strictly in terms of ground-level particulars of research design, method, strategy, and technique. Proceeding on the tacit premise that the foundations of the paradigm are basically sound, the overriding emphasis has been on fine-tuning, not fundamentals, on refinements to the protective belt, not rethinking or replacing the hard core. Not surprisingly, this methodology-as-toolbox myopia also has given rise to parallel rather than integrated lines of discourse about discovery and justification issues in mainstream psychology, each discussed in relative isolation from the other, neither with reference to the shared faulty assumptions from which they arise and to which they are tethered. An inevitable consequence of this paradigmatic scotoma is that most attempts to conceptualize psychology's methodological problems and solutions have been formulated unwittingly within the unrecognized constraints of the faulty assumptions from which the inadequacies of the methodology arise. A closer look at Meehl's Two Knights article (Meehl, 1978) discussed earlier (see Psychology's terrible difficulties) will suffice to illustrate the essence of the problem.

Paul Meehl was beside himself with disbelief in 1990 about psychology's continuing reliance on null hypothesis significance testing (NHST) as a justification standard for evaluating theoretical claims. Despite two earlier attempts to call attention to the problem, it had become increasingly clear to Meehl over the years that his arguments had fallen on deaf ears. Thus, revisiting the issue again more than a decade following his take-no-prisoners Two Knights critique, he begins by registering bafflement at the persistence of NHST and throws up his arms in despair: "This is my final attempt to call attention to a methodological problem of our field that I insist is not minor but of grave import" (Meehl, 1990a, p. 108).

Meehl still had much to say about psychology's NHST problem after 1990 and continued pressing his case for the adoption of more rigorous theory testing standards until shortly before his death (Faust \& Meehl, 2002; Meehl, 1992b, 1992c, 1995, 1997, 1998/ 2006, 2004; Waller \& Meehl, 2002). The issue that continued to puzzle him to the end, though, was the nagging question of why he and others had been unsuccessful in dislodging NHST, given its well-documented, uncontested inadequacies. Like Poe's Purloined Letter (Poe, 1845), however, the answer to Meehl's question was hiding in plain sight all along, just beneath the surface of his own arguments.

One of the most consistent and dominant themes throughout Meehl's writings on NHST and related topics was an abiding faith in the intrinsic, almost unlimited power of quantitative methods to answer complex theoretical questions in psychology when properly used. The properly qualifier is crucial here because Meehl attributed psychology's theoretical failures to misuses of quantitative methods and not to inadequacies of the methodology itself. After devoting eleven pages of the Two Knights critique to his 20features list of intrinsic subject matter difficulties-the "terrible difficulties"-of psychology, it is no accident that Meehl left them there lying in a heap as he moved on to justification issues. He viewed the methodological challenges they impose for scientific research as differing in degree, not kind, from the challenges imposed by the phenomena of the physical and biological sciences. There is no evidence of awareness either here or elsewhere in Meehl's writings that these characteristics of psychological and behavioral phenomena are inconsistent with the homogeneitycorollaries scaffolding of the paradigm's research methodology. 
Thus, with no concerns about the suitability or power of the individual differences methodology, Meehl's go-to explanations for psychology's theoretical failures were deficiencies of personnel, not the paradigm - "mathematically ignorant psychologists" (Meehl, 1990b, p. 235), a lack of "mathematically competent people in the soft areas" of psychology (Meehl, 1998/2006, p. 442), and an "Inability to think mathematically ... sometimes so gross as to be embarrassing to one familiar with the quantitative sophistication in other sciences" (Meehl, 1990b, p, 234). These quantitative inadequacies, by Meehl's lights, were reflections of a "nonmathematical intellectual tradition of soft psychology" (Meehl, 1998/2006, p. 443) engendered and perpetuated by the same institutionalized NHST practices responsible for the proliferation, short half-life, and eventual abandonment of weak substantive theories. The key to breaking this self-perpetuating cycle for Meehl was to abandon the NHST criterion for more rigorous, quantitative justification standards for evaluating theoretical claims, such as riskier point predictions, consistency tests, confidence intervals, and the like-"rules that I will almost guarantee will solve the problem without improperly censoring scholars" (Meehl, 1998/2006, p. 438).

If we follow the thread of Meehl's analysis, however, we encounter two related flaws that provide a tip-off to why his proposal never gained traction, both of which stem from his tacit reliance on the psychological homogeneity assumption and corollaries. On the problem side of his equation, he got the causal relationship between NHST and weak substantive theories exactly backward; on the solution side, the same paradigmatic scotoma leads him to the wrong prescriptive remedy. Wrong in the sense that his quantitative approach to more rigorous theory evaluation cannot work as proposed.

It is easy enough to see how psychology's excessive reliance on NHST allows weak substantive theories to survive empirically longer than they should and otherwise would. But NHST also allows strong theories to flourish and therefore poses no obstacles to their further development and refinement even as lesser theories fall by the wayside in the face of inconsistent empirical results and replication failures. By Meehl's own admission, however, this doesn't happen: "the primitive state only rarely permits strong conjectures as to the mathematical functions (let alone their parameters)" (Meehl, 1998, p. 108). But the reason they don't, contra Meehl, is that psychology's reliance on NHST is a consequence, not a cause, of its theoretical failures.

Psychologists cling to NHST because they have been unable to develop theories capable of passing empirical muster when judged by Meehl's more exacting quantitative justification standards. For reasons I elaborated earlier (see Methodological implications of psychological heterogeneity) the odds are overwhelming that any particular theoretical-causal model of psychological functioning or behavior, if it holds for anyone at all, will hold for only a subset of individuals in the population. Following the conventions of the individual differences paradigm, however, the empirical merits of such a model will be evaluated on the basis of cross-aggregate data patterns of quantitative differences between individuals who differ qualitatively from one another in unknown ways with respect to the internal psychological structures-processes and external causal factors underlying their overt functioning. Moreover, these qualitative differences are also unknowable under the vast majority of circumstances because the data analytic, statistical control and modeling tools of the paradigm are also predicated on the homogeneity-corollaries scaffolding. In other words, the theory will be evaluated on the basis of what amounts to statistical residue, theoretically uninterpretable causal debris that has equal potential for producing illusory evidence both for and against theoretical models, regardless of their substantive merits. The reason, then, that Meehl's advice for improving the mileage of psychological theories was greeted with a collective shoulder shrug by individual differences researchers is that his analysis is based on a misdiagnosis of both why their theories are stalled on the curbside and what it will take to get them back on the road.

It seems implausible on its face that one of $20^{\text {th }}$. century psychology's most gifted, influential intellects would have failed to recognize the flawed tacit premises of his own arguments. All the more implausible because of the signature breadth, depth, and rigor of Meehl's thinking and writing on the NHST problem. But it is precisely because of the clarity and thoroughness of his analysis that the psychological homogeneity assumption and corollaries underlying Meehl's arguments are so easy to identify. On the crucial question of why Meehl himself didn't recognize these assumptions, the answer was aptly summarized by C. August Dupin, the brilliant private detective in Poe's Purloined Letter (Poe, 1845) who bested the failed 3month efforts of the Parisian police Perfect to find the eponymous letter that was hiding in plain sight: 
The Parisian police ... are exceedingly able in their way ... persevering, ingenious, cunning ... The measures adopted were not only the best of their kind, but carried out to absolute perfection ... their defect lay in their being inapplicable to the case ... [They are] a sort of Procrustean bed, to which he forcibly adapts his designs (p. 7). They have no variation of principle in their investigations ... they extend or exaggerate their old modes of practice, without touching their principles ... what is it all but an exaggeration of the application of the one principle or set of principles of search (pp. 8-9).

\section{Concluding comments and redeeming methods}

I turn at last to the obvious question lurking behind the arguments and analyses of the preceding sections: What to do? If the flawed assumptions of the individual differences paradigm render it an incredible utility for yielding causal/theoretical knowledge, what would a methodologically credible utility look like? What kind of a research paradigm would be capable of shouldering the complex methodological burdens imposed by psychological and causal heterogeneity?

I gave wide berth this question throughout earlier sections for reasons that may help explain also why I will address it only in broad outline here. First, as a purely practical matter, space limitations preclude a detailed analysis of the fundamental conceptual, epistemological and ontological issues that will be necessary to negotiate in considering, developing and evaluating suitable alternatives to the individual differences methodology. The only thing worse than ignoring these issues entirely would be a summary gloss that fails to acknowledge and grapple with them in their complexity. Second, limiting the incredible utility thesis to establishing a case for the unavoidable necessity of methodological reforms also serves the strategic goal of immunizing it against beside-the-point ignoratio elenchi considerations about the suitability of particular alternatives. Methodological critiques that point to inadequacies of particular research methods and strategies are insufficient to overcome the first law of wing walking: the natural and normatively rational reluctance of psychologists to let go of what they're holding until they are holding something at least as secure. The incredible utility thesis, however, isn't about weaknesses or deficiencies of the individual differences methodology. It isn't a complaint that psychology's flood wall is poorly constructed, improperly secured, loosely fastened, or too short. Rather, it is an argument that a flood wall made of chicken wire cannot work. It can be used effectively for penning in small animals, as a minor deterrent to would-be trespassers, and-depending on wire gauge, mesh size and tensile strength-protecting structures from certain types of wind-blown debris. But chicken wire can't function as a protective barrier against flood damage. Moreover, no amount of creative tinkering or engineering prowess can alter this brute fact because it is a feature of chicken wire, not a bug. The incredible utility thesis is about the impossibility of answering causal/theoretical questions based on the individual differences methodology. It is therefore irrelevant to an evaluation of its merits and implications whether I or anyone else has yet worked out a viable alternative. The first law of wing walking doesn't apply because psychology isn't holding on to anything methodologically secure.

\section{Science in a box, no assembly required}

The challenges of methodological reform in psychology are best understood by way of analogy to the distinction between visual flight rules (VFR) and instrument flight rules (IFR) in general aviation. Under visual meteorological conditions (VMC) of clear skies and sufficient visibility, the Federal Aviation Administration permits pilots to fly aircraft according to VFR by relying exclusively on visual cues such as the horizon, terrain, buildings, and nearby aircraft as reference points for maintaining orientation and navigating safely (Federal Aviation Administration, 2017). When visibility is diminished by darkness, fog, clouds, rain, and/or other poor weather conditions, however, impoverished and conflicting cues from the visual and vestibular sensory systems can easily lead to spatial disorientation and complete loss of control. Thus, when flying under these so-called instrument meteorological conditions (IMC) pilots are required to ignore these sensory cues and operate according to IFR by relying exclusively on cockpit instruments for orientation and navigation.

American psychology took to the skies during the early decades of the $20^{\text {th }}$ century under the scientific equivalent of instrument meteorological conditions imposed by the virulently anti-metaphysical logical positivist philosophy and model of science. Logical positivism was introduced in 1929 by the Vienna Circle, an elite group of intellectuals who had taken it upon themselves to develop a formal philosophy of science that was faithful to the practices of the natural sciences, could explain their successes, and thus serve as a template for the development of other sciences. In its original and most ambitious formulation, logical 
positivism insisted that all phenomena of the natural world were qualitatively the same, relegated all talk about causes and other unobservable processes to the category of meaningless metaphysical speculation, and restricted the legitimate business of science to the description, prediction, and control of observable phenomena, a sufficiently detailed accumulation of which the logical positivists claimed would reveal the universal laws by which they were governed.

Moreover, dismissing human judgment as inherently biased and unreliable, logical positivism insisted also that the only trustworthy navigational aid to scientific activity and progress was strict adherence to a highly formalized and proceduralized deductivenomological IFR approach to identifying natural laws_-"methods by which any conflict ... is rendered superfluous; what matters is only to apply these methods resolutely" (Frank, 1950, p. 41). Causes on this account, following Hume, were equated with contingent relations between observable events; and even the ordinary language concept of understanding was rejected, such that "explaining X" was equated with "proving X to be true (or probable)" (Scriven, 1994, p. 17). Scientific theories, in turn, were to be deduced from covering (i.e., universal) laws, rationally reconstructed into deductive form, and theoretical propositions or hypotheses were to be tested formally against the facts in the service of confirming or rejecting their validity.

Logical positivism was a seductive philosophy, promising as it did an off-the-shelf, one-size-fits-all, no-assembly-required, ready-for-immediate-use, set, science-in-a-box IFR recipe for achieving scientific progress. Following a 30-year reign as the standard model of science, however, it was abandoned by midcentury scholars-including its own founders-as a logician's fancy. It couldn't be reconciled with actual practices of the successful sciences and was incapable of delivering on the promises of its IFR approach to conducting science. Psychology also renounced its anti-metaphysical commitments following the empirical disappointments of behaviorism and gradually resumed trafficking again in the once-forbidden concepts and language of holism, emergence, and unobservable causal processes (see The plumbing and wiring of individual differences methodology). By the time these transformations began to unfold, however, the IFR methodological imperatives of logical positivism had slipped their original moorings and were firmly established as functionally autonomous mainstays of psychological research. They are so seamlessly fused with psychology's foundations as a science that they continue to be retained as the implicit background assumptions of research into precisely the kinds of psychological phenomena that are possibleand inevitable-only because the assumptions are false.

\section{Staying aloft and the challenges of landing}

The rules of engagement that constrained psychology's initial development as a science were effectively nullified by the collapse of logical positivism and the subsequent ascendancy and acceptance of numerous alternative philosophies and models of science (Lamiell \& Slaney, 2021; Laudan, 1977; Manicas, 2010; Manicas \& Secord, 1983; O’Donohue et al., 2019; Richters, 1997; Robinson, 2000; Uher, 2021). No specific method, procedure, strategy, or formal rule system for either generating or evaluating knowledge claims is held out any longer as a priori scientifically superior to any other. All are judged on the basis of their fidelity to the objects, phenomena, and questions of concern to each science. Thus, psychology has been issued the equivalent of a post-positive warrant to formulate methodological reform efforts on the basis of assumptions, principles, and objectives that are at once faithful to psychological phenomena and consistent with sound canons of science. It is not a warrant for the self-indulgences of relativism, clouded thinking, or sliding scale standards of rigor that are often associated with permissive uses of so-called nontraditional research strategies and methods. Rather, it is a warrant for relinquishing psychology's adherence to logical positivism's arbitrary and discredited IFR imperatives for a time-honored principle that has guided systematic inquiry for millennia. Contrary to the logical positivist account, established sciences succeed by approaching their scientific agendas from the bottom-up, beginning with a problem and then selecting the most suitable method for solving it-which is exactly what we do in everyday life when we reach for hammers, not balloons, to pound nails; chains rather than kite string to tow cars; oxy-acetylene torches rather than votive candles to weld steel.

The most significant obstacle to methodological reforms in psychology is not the absence of suitable alternatives to the logical positivist model. Rather, it is an acquired fear of flying under the VFR clear sky conditions they permit, born of psychology's longstanding reliance on logical positivism's IFR methodological imperatives. There is much to be said for the view that fledgling psychology's embrace of these imperatives was indispensable to securing its runway 
clearance for takeoff as a science. Once established, psychology's institutional structures provided it enough lift to achieve cruising altitude and remain aloft in the face of considerable headwinds fueled by slow theoretical progress, unresolved scientific controversies, and growing public skepticism. But the flawed homogeneity-based scaffolding of the IFR-based methodology responsible for these headwinds also locked psychology into a perpetual holding pattern and renders it incapable of reaching the theoretical-causal knowledge destinations of the original flight plan.

\section{Fear of flying and the search for exits}

It would be a flight of fancy to imagine that psychologists will come easily to the evidence and arguments in support of the incredible utility thesis. A more likely reception will be the sound of methodological door rattling as psychologists search for an exit from its conclusions and implications. Those who would insist that the jury is still out on whether the psychological homogeneity assumption is false will find themselves at odds with the evidence of their own senses, their theoretical commitments, and a substantial body of uncontested science documenting the design and functioning characteristics of the human brain. To be standing knee-deep in stormwater inside a chicken wire flood wall while insisting on a formal proof that it isn't a viable barrier against runoff is to position oneself beyond the reach of rational discourse. More importantly, it would be missing the larger point. Psychological homogeneity is a troublesome assumption not only because it isn't right, but rather because it is so baseless, implausible, and untestable that, in Wolfgang Pauli's words, "it is not even wrong" (Peierls, 1960, p. 186). Untestable in the sense that it is rendered virtually unfalsifiable by the sheer number and complexity of equally problematic protective belt auxiliaries and ceteris paribus caveats that would be necessary to penetrate for an adequate evaluation of its validity with reference to even the most basic of theoretical questions (see Hard core privileges and protective belts). A virtually unfalsifiable assumption so foundational to the logic and coherence of the methodology is also a reckless one because once adopted it is virtually impossible to recognize and escape (see How the individual differences paradigm perpetuates itself).

Others will no doubt seek escape through refinements to and more creative uses of the individual differences methodology. In anticipation of these efforts, I elaborated in considerable detail throughout this article on the conceptual, theoretical, statistical reasons why we know in advance that these efforts cannot succeed. We know they can't work for the same reason Justice Mann knew that Mr. Crowley's alleged perpetual motion device couldn't produce free energy. The epistemic authority behind Justice Mann's ruling was not the laws of thermodynamics per se, but rather the fundamental reasoning principle of non-contradiction: certain established facts about the world preclude the possibility of other facts being true.

Paradigm commitments run strong and the urge to continue tinkering with the individual differences IFR methodology in pursuit of a viable glide path to causal-theoretical knowledge will be a powerful one. Thus, perhaps a more reasonable aspiration for the incredible utility thesis is that psychologists will have a more difficult time shaking the uneasy feeling that they are leaving the runway lights on for Amelia Earhart.

\section{Acknowledgments}

I am indebted to Steve Hinshaw, Everett Waters, Hope N. Riley, Tim Brennan, Mike Maltz, and David Trafimow for their helpful feedback on earlier drafts of this paper. Reaching further back, I owe a special debt of gratitude to Paul Meehl, whose early encouragement, support, and guidance was indispensable to shaping the core arguments that eventually found their way into this paper. The initial scaffolding of the incredible utility thesis was forged in the crucible of an intensive dialogue with Paul that began in 1998 with a sequestered 5-hour meeting in his D.C. hotel room and continued over the next 18 months through ongoing email, fax, and audiotape communications. Immeasurably better than it would have been without Meehl's early guidance, the final manuscript also falls far short of what it might have been had he survived through its completion. Finally, looking ahead and realizing that my thesis is a bitter pill to swallow, I'm grateful in advance to readers who resist the temptation to set it aside in favor of a critical evaluation of its supporting arguments.

\section{ORCID}

John E. Richters (D) http://orcid.org/0000-0002-6780-1828

\section{References}

[ ${ }^{*}$ References marked with an asterisk indicate empirical reports included in Table 1.]

*Aizpitarte, A., Atherton, O. E., Zheng, L. R., AlonsoArbiol, I., \& Robins, R. W. (2019). Developmental precursors of relational aggression from late childhood through adolescence. Child Development, 90(1), 117-126.

Aldrin, B., \& Abraham, K. (2010). Magnificent desolation: The long journey home from the moon. Harmony Books. 
Al-Shawaf, L., Conroy-Beam, D., Asao, K., \& Buss, D. M. (2016). Human emotions: An evolutionary psychological perspective. Emotion Review, 8(2), 173-186. https://doi. org/10.1177/1754073914565518

American Psychological Association. (2010). Publication manual of the American Psychological Association (6th ed.).

Amundson, R., \& Lauder, G. V. (1994). Function without purpose. Biology \& Philosophy, 9(4), 443-469. https://doi. org/10.1007/BF00850375

Anastasi, A. (1937). Differential psychology: Individual and group differences in behavior. The Macmillan Co.

Anda, R. F., Felitti, V. J., Bremner, J. D., Walker, J. D., Whitfield, C., Perry, B. D., Dube, S. R., \& Giles, W. H. (2006). The enduring effects of abuse and related adverse experiences in childhood. European Archives of Psychiatry and Clinical Neuroscience, 256(3), 174-186. https://doi. org/10.1007/s00406-005-0624-4

*Andretta, J. R., \& McKay, M. T. (2019). The impact of stress latent class membership and transitions on statutory service and alcohol use in adolescents across 33 months. Journal of Adolescence, 70, 53-61. https://doi. org/10.1016/j.adolescence.2018.11.005

Angell, J. R. (1907). The province of functional psychology. Psychological Review, 14(2), 61-91. https://doi.org/10. 1037/h0070817

Appelbaum, M., Cooper, H., Kline, R. B., Mayo-Wilson, E., Nezu, A. M., \& Rao, S. M. (2018). Journal article reporting standards for quantitative research in psychology: The APA Publications and Communications Board task force report. The American Psychologist, 73(1), 3-25. https://doi.org/10.1037/amp0000191

*Augustyn, M. B., Thornberry, T. P., \& Henry, K. L. (2019). The reproduction of child maltreatment: An examination of adolescent problem behavior, substance use, and precocious transitions in the link between victimization and perpetration. Development and Psychopathology, 31(1), 53-71. https://doi.org/10.1017/S0954579418001633

Babbage, C. (1830). Reflections on the decline of science in England and on some of its causes. In M. Campbell-Kelly (Ed.), The works of Charles Babbage (Vol. VII, pp. 64). William Pickering.

Bakan, D. (1966). The test of significance in psychological research. Psychological Bulletin, 66(6), 423-437. https:// doi.org/10.1037/h0020412

*Barch, D. M., Harms, M. P., Tillman, R., Hawkey, E., \& Luby, J. L. (2019). Early childhood depression, emotion regulation, episodic memory, and hippocampal development. Journal of Abnormal Psychology, 128(1), 81-95.

Barlow, F. K. (2019). Nature vs. nurture is nonsense: On the necessity of an integrated genetic, social, developmental, and personality psychology. Australian Journal of Psychology, 71(1), 68-79. https://doi.org/10.1111/ajpy. 12240

Barreiro, L. B., \& Quintana-Murci, L. (2010). From evolutionary genetics to human immunology: How selection shapes host defence genes. Nature Reviews. Genetics, 11(1), 17-30.

Bauernfeind, A. L., \& Babbitt, C. C. (2019). Genetic diversity underlying behavioral plasticity in human adaptation. Progress in Brain Research, 250, 41-58.
*Betancur, L., Rottman, B. M., Votruba-Drzal, E., \& Schunn, C. (2019). Analytical assessment of course sequencing: The case of methodological courses in psychology. Journal of Educational Psychology, 111(1), 91-103. https://doi.org/10.1037/edu0000269

Bick, J., \& Nelson, C. A. (2017). Early experience and brain development. Wiley Interdisciplinary Reviews: Cognitive Science, 8, 1-12.

Bjorklund, D. F. (2018). Behavioral epigenetics: The last nail in the coffin of genetic determinism. Human Development, 61(1), 54-59. https://doi.org/10.1159/ 000481747

Boker, S. M., Molenaar, P., \& Nesselroade, J. R. (2009). Issues in intraindividual variability: Individual differences in equilibria and dynamics over multiple time scales. Psychology and Aging, 24(4), 858-862.

Borsboom, D., Kievit, R. A., Cervone, D., \& Hood, S. B. (2009). The two disciplines of scientific psychology, or: The disunity of psychology as a working hypothesis. In J. Valsiner, P. C. M. Molenaar, M. C. D. P. Lyra, \& N. Chaudhary (Eds.), Dynamic process methodology in the social and developmental sciences (pp. 67-97). Springer.

Brennan, T. (2016). An alternative scientific paradigm for criminological risk assessment: Closed or open systems, or both?. In F. S. Taxman (Ed.), Risk and need assessment: Theory and practice (pp. 164-190). Routledge.

Burt, C. (1927). Measurement of mental capacities: A review of the psychology of individual differences. Oliver \& Boyd.

Byrd, A. L., Manuck, S. B., Hawes, S. W., Vebares, T. J., Nimgaonkar, V., Chowdari, K. V., Hipwell, A. E., Keenan, K., \& Stepp, S. D. (2019). The interaction between monoamine oxidase A (MAOA) and childhood maltreatment as a predictor of personality pathology in females: Emotional reactivity as a potential mediating mechanism. Development and Psychopathology, 31(1), 361-377. https://doi.org/10.1017/S0954579417001900

*Calhoun, B. H., Ridenour, T. A., \& Fishbein, D. H. (2019). Associations between child maltreatment, harsh parenting, and sleep with adolescent mental health. Journal of Child and Family Studies, 28(1), 116-130.

*Carter, A. (2019). The consequences of adolescent delinquent behavior for adult employment outcomes. Journal of Youth and Adolescence, 48(1), 17-29. https://doi.org/ 10.1007/s10964-018-0934-2

*Choi, K. W., Houts, R., Arseneault, L., Pariante, C., Sikkema, K. J., \& Moffitt, T. E. (2019). Maternal depression in the intergenerational transmission of childhood maltreatment and its sequelae: Testing postpartum effects in a longitudinal birth cohort. Development and Psychopathology, 31(1), 143-156. https://doi.org/10.1017/ S0954579418000032

Cisneros-Franco, J. M., Voss, P., Thomas, M. E., \& de Villers-Sidani, E. (2020). Critical periods of brain development. In Handbook of Clinical Neurology (Vol. 173, pp. 75-88). Elsevier.

Cliff, N. (1983). Some cautions concerning the application of causal modeling methods. Multivariate Behavioral Research, 18(1), 115-126. https://doi.org/10.1207/ s15327906mbr1801_7

*Collibee, C., Furman, W., \& Shoop, J. (2019). Risky interactions: Relational and developmental moderators of 
substance use and dating aggression. Journal of Youth and Adolescence, 48(1), 102-113.

Cosmides, L., \& Tooby, J. (2013). Evolutionary psychology: New perspectives on cognition and motivation. Annual Review of Psychology, 64, 201-229.

Cronbach, L. J. (1957). The two disciplines of scientific psychology. American Psychologist, 12(11), 671-684. https://doi.org/10.1037/h0043943

Cummins, R. (1975). Functional analysis. The Journal of Philosophy, 72(20), 741-765. https://doi.org/10.2307/ 2024640

Dalton, T. C., \& Bergenn, V. W. (2007). Early experience, the brain, and consciousness: An historical and interdisciplinary synthesis. Lawrence Erlbaum Associates.

Danziger, K. (1979). The positivist repudiation of Wundt. Journal of the History of the Behavioral Sciences, 15(3), 205-230. https://doi.org/10.1002/1520-6696(197907)15:3 $<205$ ::AID-JHBS2300150303>3.0.CO;2-P

Danziger, K. (1985). The methodological imperative in psychology. Philosophy of the Social Sciences, 15(1), 1-13. https://doi.org/10.1177/004839318501500101

Danziger, K. (1990). Constructing the subject: Historical origins of psychological research. Cambridge University Press.

Darwin, C. (1859). On the origin of species by means of natural selection. John Murray.

Daston, L. (1995). The moral economy of science. Osiris, 10, 2-24. https://doi.org/10.1086/368740

Eccles, J. C. (1991). Evolution of the brain: Creation of the self. Routledge.

Edelman, G. M. (1987). Neural Darwinism: A theory of neuronal group selection. Basic Books.

Edelman, G. M. (1992). Bright air, brilliant fire: On the matter of the mind. Basic Books.

Edelman, G. M., \& Gally, J. A. (2001). Degeneracy and complexity in biological systems. Proceedings of the National Academy of Sciences, 98(24), 13763-13768. https://doi.org/10.1073/pnas.231499798

Elsasser, M. W. (1981). A form of logic suited for biology. Progress in Theoretical Biology, 6, 23-62.

*Evans, S. C., \& Fite, P. J. (2019). Dual pathways from reactive aggression to depressive symptoms in children: Further examination of the failure model. Journal of Abnormal Child Psychology, 47(1), 85-97.

Faust, D., \& Meehl, P. E. (2002). Using meta-scientific studies to clarify or resolve questions in the philosophy and history of science. Philosophy of Science, 69(S3), S185-S196. https://doi.org/10.1086/341845

Federal Aviation Administration. (2017). Instrument procedures handbook. https://www.faa.gov/regulations_policies/ handbooks_manuals/aviation/instrument_procedures_ handbook/media/faa-h-8083-16b.pdf

Fox, S. E., Levitt, P., \& Nelson, C. A. III, (2010). How the timing and quality of early experiences influence the development of brain architecture. Child Development, 81(1), 28-40.

*Fragkaki, I., Cima, M., Verhagen, M., Maciejewski, D. F., Boks, M. P., van Lier, P. A. C., Koot, H. M., Branje, S. J. T., \& Meeus, W. H. J. (2019). Oxytocin receptor gene (OXTR) and deviant peer affiliation: A gene-environment interaction in adolescent antisocial behavior. Journal of Youth and Adolescence, 48(1), 86-101.
Frank, P. (1950). Modern science and its philosophy. Harvard University Press.

Frank, S. A. (2003). Genetic variation of polygenic characters and the evolution of genetic degeneracy. Journal of Evolutionary Biology, 16(1), 138-142. https://doi.org/10. 1046/j.1420-9101.2003.00485.x

Frankenhuis, W. E. (2019). Modeling the evolution and development of emotions. Developmental Psychology, 55(9), 2002-2005. https://doi.org/10.1037/dev0000732

Freedman, D. A. (1987a). As others see us: A case study in path analysis. Journal of Educational Statistics, 12(2), 101-128. https://doi.org/10.2307/1164888

Freedman, D. A. (1987b). A rejoinder on models, metaphors, and fables. Journal of Educational Statistics, 12(2), 206-223. https://doi.org/10.2307/1164900

Freedman, D. A. (1997). Rejoinder to Spirtes and Scheines. In V. R. Mc.Kim \& S. P. Turner (Eds.), Causality in crisis? Statistical and the search for causal knowledge in the social sciences (pp. 177-182). University of Notre Dame Press.

Gibson, G., \& Dworkin, I. (2004). Uncovering cryptic genetic variation. Nature Reviews. Genetics, 5(9), 681-690.

Gibson, G., \& Reed, L. K. (2008). Cryptic genetic variation. Current Biology, 18(21), R989-R990.

Gilliand, A. R., \& Clark, E. L. (1939). The psychology of individual differences. Prentice-Hall.

Goethe, J. W. (1792). The experiment as mediator between object and subject. In D. Miller (Ed. and Trans.), Scientific studies (p. 14). Suhrkamp.

Gottlieb, G. (1991). Experimental canalization of behavioral development: Theory. Developmental Psychology, 27(1), 4-13. https://doi.org/10.1037/0012-1649.27.1.4

Gottlieb, G. (2002). Developmental-behavioral initiation of evolutionary change. Psychological Review, 109(2), 211-218. https://doi.org/10.1037/0033-295x.109.2.211

Gottlieb, G. (2007). Probabilistic epigenesis. Developmental Science, 10(1), 1-11. https://doi.org/10.1111/j.1467-7687. 2007.00556.X

Greenough, W., Black, J., \& Wallace, C. (1987). Experience and brain development. Child Development, 58(3), 539-559.

*Ha, T., Otten, R., McGill, S., \& Dishion, T. J. (2019). The family and peer origins of coercion within adult romantic relationships: A longitudinal multimethod study across relationships contexts. Developmental Psychology, 55(1), 207-215.

Harris, R. M., O"Connell, L. A., \& Hofmann, H. A. (2017). Brain evolution, development, and plasticity. In S. V. Shepherd (Ed.), The Wiley handbook of evolutionary neuroscience (pp. 422-443). Wiley-Blackwell.

Haslam, N., Holland, E., \& Kuppens, P. (2012). Categories versus dimensions in personality and psychopathology: A quantitative review of taxometric research. Psychological Medicine, 42(5), 903-920.

Holland, P. W. (1986). Statistics and causal inference. Journal of the American Statistical Association, 81(396), 945-960. https://doi.org/10.1080/01621459.1986.10478354

Hull, C. L. (1925). An automatic correlation calculating machine. Journal of the American Statistical Association, 20(152), 522-531. https://doi.org/10.1080/01621459.1925. 10502926 
James, W. (1890a). The principles of psychology (Vol. 1). MacMillan \& Co, Ltd.

James, W. (1890b). The principles of psychology (Vol. 2). MacMillan \& Co, Ltd.

James, W. (1892). A plea for psychology as a "natural science". The Philosophical Review, 1(2), 146-153. https:// doi.org/10.2307/2175743

*Khafi, T. Y., Borelli, J. L., \& Yates, T. M. (2019). Prospective associations between maternal self-sacrifice/ overprotection and child adjustment: Mediation by insensitive parenting. Journal of Child and Family Studies, 28(1), 202-217. https://doi.org/10.1007/s10826018-1245-7

Kioussis, D., \& Pachnis, V. (2009). Immune and nervous systems: More than just a superficial similarity. Immunity, 31(5), 705-710. https://doi.org/10.1016/j. immuni.2009.09.009

Koslow, S. H., Meinecke, D. L., Lederhendler, I. I., Khachaturian, H., Nakamura, R. K., \& Karp, D. (1995). The neuroscience of mental health II: A report on neuroscience research: Status and potential for mental health and mental illness (NIH Pub. No. 95-4000). USDHHS, Public Health Service and the National Institutes of Health.

Kuhn, T. S. (1970). The structure of scientific revolutions (2nd enlarged edition). University of Chicago Press.

*Labella, M. H., Raby, K. L., Martin, J., \& Roisman, G. I. (2019). Romantic functioning mediates prospective associations between childhood abuse and neglect and parenting outcomes in adulthood. Development and Psychopathology, 31(1), 95-111.

Ladd, G. T. (1892). Psychology as so-called "natural science". The Philosophical Review, 1(1), 24-53. https://doi. org/10.2307/2175528

Lakatos, I. (1980). A methodology of scientific research programmes. In J. Worrall \& G. Currie (Eds.). Imre Lakatos: Philosophical papers, The methodology of scientific research programmes (Vol. 1). Cambridge University Press.

Lamiell, J. T., \& Slaney, K. L. (Eds.), (2021). Problematic research practices and inertia in scientific psychology: History, sources, and recommended solutions. Routledge.

Laudan, L. (1977). From theories to research traditions. In L. Laudan (Ed.), Progress and its problems: Toward a theory of scientific growth (pp. 368-379). University of California Press.

Laurent, P., Jolivel, V., Manicki, P., Chiu, L., Contin-Bordes, C., Truchetet, M. E., \& Pradeu, T. (2017). Immune-mediated repair: A matter of plasticity. Frontiers in Immunology, 8, 454.

*Lee, J. O., Jones, T. M., Yoon, Y., Hackman, D. A., Yoo, J. P., \& Kosterman, R. (2019). Young adult unemployment and later depression and anxiety: Does childhood neighborhood matter? Journal of Youth and Adolescence, 48(1), 30-42.

Lent, R., \& Tovar-Moll, F. (2015). How can development and plasticity contribute to understanding evolution of the human brain? Frontiers in Human Neuroscience, 9, 208-202.

Lerner, R. M., \& Overton, W. F. (2017). Reduction to absurdity: Why epigenetics invalidates all models involving genetic reduction. Human Development, 60(2-3), 107-123. https://doi.org/10.1159/000477995

Lickliter, R., \& Witherington, D. C. (2017). Towards a truly developmental epigenetics. Human Development, 60(2-3), 124-138. https://doi.org/10.1159/000477996

Lindenberger, U., \& Lövdén, M. (2019). Brain plasticity in human lifespan development: The exploration-selectionrefinement model. Annual Review of Developmental Psychology, 1(1), 197-222. https://doi.org/10.1146/ annurev-devpsych-121318-085229

Linderkamp, O., \& Linderkamp-Skoruppa, D. B. (2021). Prenatal structural brain development: Genetic and environmental determinants. In K. Everetts, L. Janus, \& R. Linder (Eds), Handbook of prenatal and perinatal psychology (pp. 19-32). Springer.

*Lombardi, C. M., Coley, R. L., Sims, J., Lynch, A. D., \& Mahalik, J. R. (2019). Social norms, social connections, and sex differences in adolescent mental and behavioral health. Journal of Child and Family Studies, 28(1), 91-104. https://doi.org/10.1007/s10826-018-1253-7

*Lorenzo-Blanco, E. I., Meca, A., Unger, J. B., Szapocznik, J., Cano, M. Á., Des Rosiers, S. E., \& Schwartz, S. J. (2019). Cultural stress, emotional well-being, and health risk behaviors among recent immigrant Latinx families: The moderating role of perceived neighborhood characteristics. Journal of Youth and Adolescence, 48(1), 114-131. https://doi.org/10.1007/s10964-018-0907-5

*Lowe, M. R., Marmorstein, N., Iacono, W., Rosenbaum, D., Espel-Huynh, H., Muratore, A. F., Lantz, E. L., \& Zhang, F. (2019). Body concerns and BMI as predictors of disordered eating and body mass in girls: An 18-year longitudinal investigation. Journal of Abnormal Psychology, 128(1), 32-43.

Lykken, D. T. (1991). What's wrong with psychology, anyway?. In D. Cicchetti \& W. Grove (Eds.), Thinking clearly about psychology (Vol. 1, pp. 3-39). University of Minnesota Press.

Lykken, D. T. (2004). Paul Everett Meehl. Applied and Preventive Psychology, 11(1), 53-56. https://doi.org/10. 1016/j.appsy.2004.02.017

*Ma, D., Serbin, L. A., \& Stack, D. M. (2019). How children's anxiety symptoms impact the functioning of the hypothalamus-pituitary-adrenal axis over time: A crosslagged panel approach using hierarchical linear modeling. Development and Psychopathology, 31(1), 309-323.

Mackie, J. L. (1974). The cement of the universe: A study of causation. Oxford University Press.

MacLean, E. L. (2016). Unraveling the evolution of uniquely human cognition. Proceedings of the National Academy of Sciences of the United States of America, 113(23), 6348-6354. https://doi.org/10.1073/pnas.1521270113

Maleszka, R., Mason, P. H., \& Barron, A. B. (2014). Epigenomics and the concept of degeneracy in biological systems. Briefings in Functional Genomics, 13(3), 191-202.

Malnic, B., Gonzalez-Kristeller, D. C., \& Gutiyama, L. M. (2010). Odorant receptors. Neurobiology of Olfaction, 181-202.

Manicas, P. T. (2010). Interaction of theory and method in social science. Historical Developments and Theoretical Approaches in Sociology, 1, 126-158. 
Manicas, P. T., \& Secord, P. F. (1983). Implications for psychology of the new philosophy of science. American Psychologist, 4, 399-413.

Marcus, G., Marblestone, A., \& Dean, T. (2014). The atoms of neural computation. Science, 346(6209), 551-552.

*Mars, B., Heron, J., Klonsky, E. D., Moran, P., O’Connor, R. C., Tilling, K., Wilkinson, P., \& Gunnell, D. (2019). What distinguishes adolescents with suicidal thoughts from those who have attempted suicide? A populationbased birth cohort study. Journal of Child Psychology and Psychiatry, and Allied Disciplines, 60(1), 91-99.

* Martin-Storey, A., \& Fish, J. (2019). Victimization disparities between heterosexual and sexual minority youth from ages 9 to 15. Child Development, 90(1), 71-81.

Mason, P. H. (2010). Degeneracy at multiple levels of complexity. Biological Theory, 5(3), 277-288. https://doi.org/ 10.1162/BIOT_a_00041

Mason, P. H. (2015). Degeneracy: Demystifying and destigmatizing a core concept in systems biology. Complexity, 20(3), 12-21. https://doi.org/10.1002/cplx.21534

Mayr, E. (1964). The determinants and evolution of life. The evolution of living systems. Proceedings of the National Academy of Sciences of the United States of America, 51, 934-941. https://doi.org/10.1073/pnas.51.5. 934

McLaughlin, K. A., Weissman, D., \& Bitrán, D. (2019). Childhood adversity and neural development: A systematic review. Annual Review of Developmental Psychology, $1,277-312$.

*McLean, K., Wolfe, S. E., \& Pratt, T. C. (2019). Legitimacy and the life course: An age-graded examination of changes in legitimacy attitudes over time. Journal of Research in Crime and Delinquency, 56(1), 42-83. https:// doi.org/10.1177/0022427818793934

Meehl, P. E. (1954). Clinical vs. statistical prediction: A theoretical analysis and review of the evidence. University of Minnesota Press.

Meehl, P. E. (1970). Nuisance variables and the ex post facto design. In M. Radner \& S. Winokur (Eds), Analyses of theories and methods of physics and psychology (pp. 373-402). University of Minnesota Press.

Meehl, P. E. (1971). High school yearbooks: A reply to Schwarz. Journal of Abnormal Psychology, 77(2), 143-148. https://doi.org/10.1037/h0030750

Meehl, P. E. (1978). Theoretical risks and tabular asterisks: Sir Karl, Sir Ronald, and the slow progress of soft psychology. Journal of Consulting and Clinical Psychology, 46(4), 806-834. https://doi.org/10.1037/0022-006X.46.4. 806

Meehl, P. E. (1990a). Appraising and amending theories: The strategy of Lakatosian defense and two principles that warrant it. Psychological Inquiry, 1(2), 108-141. https://doi.org/10.1207/s15327965pli0102_1

Meehl, P. E. (1990b). Why summaries of research on psychological theories are often uninterpretable. Psychological Reports, 66(1), 195-244. https://doi.org/10. 2466/pr0.1990.66.1.195

Meehl, P. E. (1992a). Factors and taxa, traits and types, difference of degree and differences in kind. Journal of Personality, 60(1), 117-174. https://doi.org/10.1111/j. 1467-6494.1992.tb00269.x
Meehl, P. E. (1992b). Cliometric metatheory: The actuarial approach to empirical, history-based philosophy of science. Psychological Reports, 71, 339-467.

Meehl, P. E. (1992c). The miracle argument for realism: An important lesson to be learned by generalizing from Carrier's counterexamples. Studies in History and Philosophy of Science Part A, 23(2), 267-282. https://doi. org/10.1016/0039-3681(92)90035-5

Meehl, P. E. (1995). Bootstraps taxometrics: Solving the classification problem in psychopathology. American Psychologist, 50(4), 266-275. https://doi.org/10.1037/0003066X.50.4.266

Meehl, P. E. (1997). The problem is epistemology, not statistics: Replace significance tests by confidence intervals and quantify accuracy of risky numerical predictions. In L. L. Harlow, S. A. Mulaik \& J. H. Steiger (Eds.), What if there were no significance tests? (pp. 393-425). LEA.

Meehl, P. E. (2004). Cliometric metatheory III: Peircean consensus, verisimilitude, and asymptotic method. The British Journal for the Philosophy of Science, 55(4), 615-643. https://doi.org/10.1093/bjps/55.4.615

Meehl, P. E. (2006). The power of quantitative thinking. In N. G. Waller, L. J. Yonce, W. M. Grove, D. Faust \& M. F. Lenzenweger (Eds.), A Paul Meehl reader: Essays on the practice of scientific psychology (pp. 433-444). Erlbaum. (Original work published 1998)

* Meter, D. J., Ehrenreich, S. E., \& Underwood, M. K. (2019). Relations between parent psychological control and parent and adolescent social aggression. Journal of Child and Family Studies, 28(1), 140-151. https://doi.org/ 10.1007/s10826-018-1240-Z

Miettunen, J., Nordström, T., Kaakinen, M., \& Ahmed, A. O. (2016). Latent variable mixture modeling in psychiatric research: A review and application. Psychological Medicine, 46(3), 457-467.

Mill, J. S. (1843). A system of logic ratiocinative and inductive. Being a connected view of the principles of evidence and the methods of scientific. Volume 8 of Collected works of John Stuart Mill. Liberty Fund.

*Miller, N. V., Degnan, K. A., Hane, A. A., Fox, N. A., \& Chronis-Tuscano, A. (2019). Infant temperament reactivity and early maternal caregiving: Independent and interactive links to later childhood attention-deficit/ hyperactivity disorder symptoms. Journal of Child Psychology and Psychiatry, and Allied Disciplines, 60(1), 43-53.

Molenaar, P. C. M., \& Ram, N. (2009). Advances in dynamic factor analysis of psychological processes. In J. Valsiner, P. C. M. Molenaar, M. C. D. P. Lyra \& N. Chaudhary (Eds.), Dynamic process methodology in the social and developmental sciences (pp. 255-268). Springer.

*Musci, R. J., Bettencourt, A. F., Sisto, D., Maher, B., Masyn, K., \& Ialongo, N. S. (2019). Violence exposure in an urban city: A GxE interaction with aggressive and impulsive behaviors. Journal of Child Psychology and Psychiatry, 60(1), 72-81. https://doi.org/10.1111/jcpp. 12966

*Na, C., \& Paternoster, R. (2019). Prosocial identities and youth violence. Journal of Research in Crime and Delinquency, 56(1), 84-128. https://doi.org/10.1177/0022 427818796552 
Nagel, E. (1977). Functional explanations in biology. The Journal of Philosophy, 74(5), 280-301. https://doi.org/10. 2307/2025746

Nakajima, K., \& Morimoto, K. (2019). Role of the immune system in the development of the central nervous system. Frontiers in Neuroscience, 13, 911-916.

*Narr, R. K., Allen, J. P., Tan, J. S., \& Loeb, E. L. (2019). Close friendship strength and broader peer group desirability as differential predictors of adult mental health. Child Development, 90(1), 298-313.

Neander, K. (1991). Functions as selected effects: The conceptual analyst's defense. Philosophy of Science, 58(2), 168-184. https://doi.org/10.1086/289610

New York Times. (1990, July 1). Calamities in space. Section 1. Editorial desk, p. 16.

Noppeney, U., Friston, K. J., \& Price, C. J. (2004). Degenerate neuronal systems sustaining cognitive functions. Journal of Anatomy, 205(6), 433-442. https://doi. org/10.1111/j.0021-8782.2004.00343.x

O’Donohue, W. T., Burleigh, K., \& Kinzler, A. D. (2019). Capturing the unique nature of the human sciences: The second demarcation problem. Behavior and Philosophy, $47,15-33$.

Overton, W. F. (2013). A new paradigm for developmental science: Relationism and relational-developmental systems. Applied Developmental Science, 17(2), 94-107. https://doi.org/10.1080/10888691.2013.778717

Oyama, S. (2000). Evolution's eye: A systems view of biologyculture divide. Duke University Press.

* Parker, P. D., Marsh, H. W., Thoemmes, F., \& Biddle, N. (2019). The negative year in school effect: Extending scope and strengthening causal claims. Journal of Educational Psychology, 111(1), 118-132. https://doi.org/ 10.1037/edu0000270

Peierls, R. (1960). Wolfgang Ernst Pauli. 1900-1958. Biographical Memoirs of Fellows of the Royal Society, 5, 175-192.

Perry, B. D., Pollard, R. A., Blakley, T. L., Baker, W. L., \& Vigilante, D. (1995). Childhood trauma, the neurobiology of adaptation, and "use-dependent" development of the brain: How "states" become "traits". Infant Mental Health Journal, 16(4), 271-291. https://doi.org/10.1002/10970355(199524)16:4<271::AID-IMHJ2280160404>3.0.CO;2-B

*Perry, K. J., \& Ostrov, J. M. (2019). The reciprocal relations between female and male play partners and aggression in early childhood. Child Development, 90(1), 127-135.

Peter Crowley v. Comptroller General of Patents, Designs and Trade Marks, EWHC 3871 (2014).

Poe, A. E. (1845). The purloined letter. In P.V. Doren Stern (Ed.), The portable Poe (pp. 439-462). Penguin Books.

Porter, T. M. (1996). Trust in numbers: The pursuit of objectivity in science and public life. Princeton University Press.

Price, C. J., \& Friston, K. J. (2002). Degeneracy and cognitive anatomy. Trends in Cognitive Sciences, 6(10), 416-421.

Richters, J. E. (1997). The Hubble hypothesis and the developmentalist's dilemma. Development and Psychopathology, 9(2), 193-229. https://doi.org/10.1017/ s0954579497002022
Richters, J. E., \& Cicchetti, D. (1993a). Editorial: Toward a developmental perspective on conduct disorder. Development and Psychopathology, 5(1-2), 1-4. https:// doi.org/10.1017/S0954579400004223

Richters, J. E., \& Cicchetti, D. (1993b). Mark Twain meets DSM-III-R: Conduct disorder, development, and the concept of harmful dysfunction. Development and Psychopathology, 5(1-2), 5-29. https://doi.org/10.1017/ S0954579400004235

Robinson, D. N. (2000). Paradigms and the myth of framework: How science progresses. Theory \& Psychology, 10, 39-47.

Rogosa, D. (1980). A critique of cross-lagged correlation. Psychological Bulletin, 88(2), 245-258. https://doi.org/10. 1037/0033-2909.88.2.245

Schlindler, B. A. (1985). Stress, affective disorders, and immune function. Medical Clinics of North America, 69, 585-597.

Scriven, M. (1994). The psycho-logical foundations of modern science. In W. W. Harman \& J. Clark (Eds.), The new metaphysical foundations of modern science (pp. 47-79). Noetic Sciences Institute.

*Shen, Y., Kim, S. Y., \& Benner, A. D. (2019). Burdened or efficacious? Subgroups of Chinese American language brokers, predictors, and long-term outcomes. Journal of Youth and Adolescence, 48(1), 154-169. https://doi.org/10. 1007/s10964-018-0916-4

*Suor, J. H., Sturge-Apple, M. L., \& Jones-Gordils, H. R. (2019). Parsing profiles of temperamental reactivity and differential routes to delay of gratification: A personbased approach. Development and Psychopathology, 31(1), 341-360

*Teng, Z., Nie, Q., Guo, C., Zhang, Q., Liu, Y., \& Bushman, B. J. (2019). A longitudinal study of link between exposure to violent video games and aggression in Chinese adolescents: The mediating role of moral disengagement. Developmental Psychology, 55(1), 184-195.

The Inventor's Department. (1911). A new patent office ruling on perpetual motion machines. Scientific American, 105, 561-562.

Thorndike, E. L. (1911). Individuality. Houghton Mifflin Company.

Thorndike, E. L. (1918). Individual differences. Psychological Bulletin, 15(5), 148-159. https://doi.org/10.1037/h0070314

Tononi, G., Sporns, O., \& Edelman, G. M. (1999). Measures of degeneracy and redundancy in biological networks. Proceedings of the National Academy of Sciences, 96(6), 3257-3262. https://doi.org/10.1073/pnas.96.6.3257

Tooley, U. A., Bassett, D. S., \& Mackey, A. P. (2021). Environmental influences on the pace of brain development. Nature Reviews. Neuroscience, 22(6), 372-384.

*Trinh, S. L., Lee, J., Halpern, C. T., \& Moody, J. (2019). Our buddies, ourselves: The role of sexual homophily in adolescent friendship networks. Child Development, 90(1), e132-e147.

Uher, J. (2021). Psychology's status as a science: Peculiarities and intrinsic challenges. Moving beyond its current deadlock towards conceptual integration. Integrative Psychological and Behavioral Science, 55(1), $212-224$

United States Patent and Trademark Office (2019). Guidelines for examination of applications for 
compliance with the utility requirement [R-10.2019]. Manual of patent examining procedure, Ninth Edition. United States Government Printing Office.

*Vertsberger, D., \& Knafo-Noam, A. (2019). Mothers' and fathers' parenting and longitudinal associations with children's observed distress to limitations: From pregnancy to toddlerhood. Developmental Psychology, 55(1), 123-134.

Waller, N. G., \& Meehl, P. E. (2002). Risky tests, verisimilitude, and path analysis. Psychological Methods, 7(3), 323-337. https://doi.org/10.1037/1082-989X.7.3.323

*Wang, Y., Cham, H., Aladin, M., \& Yip, T. (2019). Parental cultural socialization and adolescent private regard: Exploring mediating pathways through daily experiences. Child Development, 90(1), e19-e36.

West, S. G., \& Biesanz, J. C., \& Pitts, S. C. (2000). Causal inference and generalization in field settings: Experimental and quasi-experimental designs. In $\mathrm{H}$. T. Reis \& C. M. Judd (Eds.), Handbook of research methods in social and personality psychology (pp. 40-84). Cambridge University Press.

West, S. G., \& Thoemmes, F. (2010). Campbell's and Rubin"s perspectives on causal inference. Psychological Methods, 15(1), 18-37.

West-Eberhard, M. J. (2003). Developmental plasticity and evolution. Oxford University Press.

Whitacre, J. (2010). Degeneracy: A link between evolvability, robustness and complexity in biological systems. Theoretical Biology \& Medical Modelling, 7, 6-17. https:// doi.org/10.1186/1742-4682-7-6

Whitacre, J., \& Bender, A. (2010). Degeneracy: A design principle for achieving robustness and evolvability. Journal of Theoretical Biology, 263(1), 143-153.

Whitacre, J. M., \& Atamas, S. P. (2012). Degeneracy allows for both apparent homogeneity and diversification in populations. Bio Systems, 110(1), 34-42.

Wigley, I. L. C. M., Mascheroni, E., Peruzzo, D., Giorda, R., Bonichini, S., \& Montirosso, R. (2021). Neuroimaging and DNA methylation: An innovative approach to study the effects of early life stress on developmental plasticity. Frontiers in Psychology, 12, 1-13.
Wilkinson, L. (1999). Statistical methods in psychology journals: Guidelines and explanations. American Psychologist, 54(8), 594-603. https://doi.org/10.1037/0003066X.54.8.594

Wilson, D. S., Hayes, S. C., Biglan, A., \& Embry, D. D. (2014). Evolving the future: Toward a science of intentional change. Behavioral and Brain Sciences, 37(4), 395-416. https://doi.org/10.1017/S0140525X13001593

Witherington, D. C., \& Boom, J. (2019a). Conceptualizing the dynamics of development in the 21st century: Process, (inter) action, and complexity. Human Development, 63(Suppl. 3-4), 147-152. https://doi.org/10. $1159 / 000504097$

Witherington, D. C., \& Boom, J. (2019b). Developmental dynamics: Past, present, and future. Human Development, 63(Suppl. 3-4), 264-276. https://doi.org/10.1159/ 000504319

Wright, L. (1973). Functions. The Philosophical Review, 82(2), 139-168. https://doi.org/10.2307/2183766

Xie, Y. (2011). Causal inference and heterogeneity bias in social science. Information, Knowledge, Systems Management, 10(1), 279-289. https://doi.org/10.3233/IKS2012-0197

Yirmiya, R., \& Goshen, I. (2011). Immune modulation of learning, memory, neural plasticity and neurogenesis. Brain, Behavior, and Immunity, 25(2), 181-213.

*Zajac, L., Raby, K. L., \& Dozier, M. (2019). Attachment state of mind and childhood experiences of maltreatment as predictors of sensitive care from infancy through middle childhood: Results from a longitudinal study of parents involved with child protective services. Development and Psychopathology, 31(1), 113-125.

*Zhou, X., Lee, R. M., \& Syed, M. (2019). Ethnic identity developmental trajectories during the transition to college. Developmental Psychology, 55(1), 157-169. https:// doi.org/10.1037/dev0000634

*Zubizarreta, A., Calvete, E., \& Hankin, B. L. (2019). Punitive parenting style and psychological problems in childhood: The moderating role of warmth and temperament. Journal of Child and Family Studies, 28(1), 233-244. https://doi.org/10.1007/s10826-018-1258-2 